\title{
Dual Fuel Diesel Combustion with an E85 Ethanol/Gasoline Blend
}

\author{
Authors: \\ Corresponding author: \\ Sarjovaara, Teemu Aalto University \\ Aalto University \\ Department of Energy Technology \\ P.O. Box 14300 \\ 00076 AALTO \\ Finland \\ teemu.sarjovaara@aalto.fi \\ $+358503012039$ \\ Larmi, Martti Aalto University \\ Aalto University \\ Department of Energy Technology \\ P.O. Box 14300 \\ 00076 AALTO \\ Finland \\ martti.larmi@aalto.fi \\ $+358505695625$
}

(C) 2014. This manuscript version is made available under the Elsevier user license http:/www.elsevier.com/open-access/userlicense/1.0/ 


\begin{abstract}
In this experimental study, the ethanol/gasoline blend E85 was used as the primary fuel in a dual-fuel combustion concept. The E85 blend was injected at low pressure into the intake manifold and the mixture was ignited via a diesel fuel injection near top dead centre. The research engine was based on a heavy-duty diesel engine equipped with a common-rail injection system. Only the duration of the diesel injection was modified in the diesel injection system during the tests - the other diesel injection parameters were not changed. The goal was to study the possibilities of using the waste material-based E85 ethanol blend on dual-fuel concept as a promising future bio-fuel option. The results were promising, though the engine was not optimised for the combustion concept being studied and minimum modifications were done to the engine. High E85 rates (up to 89\%) by energy content were achieved, especially under medium load conditions. On the high and low load portions were lower, but the E85 rates were higher than $30 \%$ even in these cases. For most of the cases, the limiting issue was the pressure rise rate, but in cases with the highest portions of E85 the limiting factor was the minimum quantity of the diesel fuel enabling two phase diesel fuel injection. In all cases the E85 increased carbon-monoxide and un-burned hydrocarbon emission, but the nitrogen oxide emission decreased simultaneously in most of the cases. Smoke emissions were low in all cases, but at highest E85 rate smoke emissions further decreased to near zero value.
\end{abstract}

\title{
Keywords
}

Dual fuel, ethanol, E85, Diesel, Combustion

\section{Introduction}

The outlook of world energy markets has changed radically during the last few years. The main concerns and motivations for moving towards alternative fuels have been limited crude oil reserves and climate change. Currently the development of shale gas pumping technology has changed the outlook radically - from technological, market and political points of view [1-4].

To this day, compression ignition (CI) engines using diesel fuel have been the main power sources of both on-road and off-road heavy duty vehicles. Their conditions of use set high demands for engine efficiency, fuel price and fuel energy density and storage properties. However, CI engines that use traditional crude oil-based diesel fuel are facing new challenges in the form of uncertainties regarding diesel fuel prices and meeting strict emission legislation for particulates and nitrogen oxides. Since transportation consumes a significant portion of total world energy consumption [3], it is both environmentally and economically important to develop alternatives for crude oil-based diesel fuel in this market area.

The exploitation of shale gas has increased interest in natural gas (NG) as a transport fuel. However, gaseous fuel has a drawback compared to traditional liquid fuels. The biggest challenges to using more NG are its low energy content on gaseous phase and the limited distribution infrastructure currently in place. The challenge with respect to energy density can be partly avoided by liquefying the gas, but the process consumes energy and liquefied natural gas (LNG) also requires a specific distribution infrastructure because it is liquefied using cryogenic technology. [5,6]

The dual fuel concept for NG was originally introduced several decades ago. With dual-fuel combustion, the primary fuel is injected into the intake manifold at low pressure, and it is ignited by injecting diesel fuel into the cylinder near the top-dead-centre (TDC). [7] The concept is similar to the spark ignition (SI) process, but instead of an electric spark the combustion of gas is initiated with a small amount of diesel fuel injected at the TDC and ignited by the heat from the compression of the charge. A similar combustion concept as the one used with NG can also be used with liquid fuels that have their ignition properties close to the NG. These liquid fuels typically used as spark ignition engine fuels. [5]

The NG dual fuel technology has mainly been used at power plants near natural gas sources or pipelines and pipeline compressor stations. The dual fuel engines were introduced for maritime markets at the same time that LNG tankers were developed in the early 1990s. More recently, the upcoming International Maritime Organization (IMO) Tier III regulations have been a driving force for dual fuel ship application development. Since NG does not contain any sulphur, the sulphur oxide $\left(\mathrm{SO}_{\mathrm{x}}\right)$ emissions are zero, which is quite important in terms of specific Sulphur Emission 
Control Areas (SECA), where will enforce strict $\mathrm{SO}_{\mathrm{x}}$ limits in the few years [8]. The lean-burn dual fuel gas engines have very low nitrogen-oxides $\left(\mathrm{NO}_{\mathrm{x}}\right)$ and soot emissions, and they can fulfil emission demands without the need for additional exhaust gas after-treatment systems in a ship use.

Natural gas has not become popular for both on-road and off-road applications because of the challenges related to distribution and energy density. Since NG prices have recently decreased due to the presence of shale gas in the US, NG dual-fuel has also been the subject of increasing interest in road transport. Though the dual fuel concept has traditionally been perceived as natural gas combustion, there are several liquid fuels that have been studied in dual fuel combustion: ethanol [9-17], methanol [18-22], butanol [23] Liquefied Petroleum Gas (LPG)/propane [24-26] and gasoline [27,28]. A common feature of these three fuels is that they are all well suited for SI engines and have similar combustion characteristics, e.g. a high octane number and low cetane number.

The objective of this study is to utilise the dual fuel concept to study the liquid blend of ethanol and gasoline most commonly called E85, which contains a maximum of $85 \%$ ethanol by volume. The motivation for using E85 is based on the fuel's higher energy content and the fact that it has a simpler distribution and storage infrastructure and lower carbon-dioxide $\left(\mathrm{CO}_{2}\right)$ emissions compared to NG. E85 is also an interesting fuel grade since it is already publicly available on some markets in Northern America and in Europe. The $\mathrm{CO}_{2}$ emissions are lower since blended ethanol is typically manufactured from field crops or waste-based biomass. The E85 blend has been developed for SI engines, and the reason for mixing $15 \%$ light hydrocarbons with ethanol is to improve the cold start driveability of the engines [29].

As mentioned earlier, several fuels have been studied as alternatives for the dual fuel combustion. There are also many studies [29-31] focusing on how E85 performs in SI engines, but the writers are not aware of any earlier studies on E85 as a dual fuel combustion fuel. There are several studies on the effects of E85 on a reactivity controlled compression ignition (RCCI) combustion strategy [32,33], but since RCCI differs from the dual fuel concept employed in this study, it is not discussed further here.

In this study, we investigated the capability of E85 to affect the dual fuel combustion. The studies were performed using a heavy-duty diesel engine equipped with a port fuel injection system for E85. The engine was not optimised for the E85 dual fuel combustion and the diesel injection parameters were left as the engine manufacturer originally defined them.

\section{Background}

Ethanol, as also other alcohols like methanol and butanol, has a low cetane number, so it is not a suitable substitute for diesel fuel in CI engines without ignition-improving additives, which are required by as much as $16 \%$ by volume to ensure compression ignition [5]. The advantages of ethanol, e. g. its high oxygen content (34.8 wt.-\%), have been utilised in CI engines by blending it with diesel fuel and injecting it in the same way as in a normal diesel engine [5,9,34,35]. Abu-Qudais et al. [9] found that up to $25 \%$ ethanol displacement can be achieved by blending when using emulsifiers, although they reported that $15 \%$ was the optimum blend. In another study by Lei et al. [34], displacements of up to $30 \%$ were achieved. In practice, a diesel/ethanol blend always demands additives because of its poor solubility, and with higher than $10 \%$ ethanol content, ignition improvers are also needed to ensure proper ignition behaviour [5].

Ethanol mixes poorly with fossil diesel fuel due to the presence of paraffinic compounds, but it can be blended with biodiesels, which have a different hydrocarbon profile than fossil diesel fuel, without additives [36]. In studies by Beatrice et al. [37] and Silveira et al. [36], fat acid methyl esters (FAME) were used as blending agents to blend alcohols with fossil diesel fuel. Beatrice et al. conducted engine tests with a 20\% ethanol / 10\% FAME diesel blend and found that it strongly reduced smoke and $\mathrm{NO}_{\mathrm{x}}$ emissions [37]. Silveira et al. studied the solubility of alcohol/FAME/diesel blends with liquid-liquid equilibrium curves at two different temperatures. They found that temperature increases alcohol solubility and that ethanol has better solubility than methanol [36]. Zhu et al. [38] studied a blend of $20 \%$ ethanol in soy bean-based FAME at a premixed low temperature combustion (LTC). They found lower smoke levels than with $100 \%$ diesel fuel or FAME and were also able to extend the LTC operating range from 0.4-0.65 to $0.35-0.82 \mathrm{MPa}$ indicated mean effective pressure (IMEP) [38].

Methanol has very similar behaviour as ethanol, when it is mixed with diesel fuel. Its miscibility with diesel fuel is poor, while low cetane number and high heat of vaporization impair its ignition behaviour. [5] Sayin et al. [39] studied 
methanol diesel fuel blends with 0.4 litre single cylinder naturally aspired diesel engine. The main focus of their study was on the influence of the diesel injection parameters on engine performance and emissions. As they increased the amount of methanol in the fuel, the $\mathrm{NO}_{\mathrm{x}}$ emissions increased while brake thermal efficiency (BTE), carbon-monoxide (CO) and total unburned hydro-carbon (THC) emission decreased. The highest BTE was found with original injection parameters, while there was clear trade of between $\mathrm{NO}_{\mathrm{x}}$ and other emissions when the parameters were adjusted. [39]

Butanol has advantages over ethanol and methanol. It has higher cetane number (25) than ethanol or methanol, lower heat of vaporization and higher heating value. Butanol also blends well with diesel fuel. Yilmaz et al. [40] studied diesel-biodiesel-butanol blends and their effect on emissions and performance values with 0.479 litre two-cylinder naturally aspired diesel engine. They found that butanol blending with biodiesel decreased $\mathrm{NO}_{\mathrm{x}}$ emissions while it increased $\mathrm{CO}$ and THC emissions. When butanol was blended with fossil based diesel fuel the $\mathrm{NO}_{\mathrm{x}}$ emission increased and $\mathrm{CO}$ was lower, while it had no significant effect on THC emission. Butanol also increased specific fuel consumption in their study. [40]

Zhang et. al. [41] studied effect of the butanol diesel blends on particulate emissions. Their study was made with single cylinder naturally aspired engine with cylinder volume of 0.296 litre. The increase of butanol in the fuel decreased particulate mass and elemental carbon emissions, while proportion of organic carbon increased at the same. They also found that total number of particles, both volatile and non-volatile, reduced, while the number of the particles with diameter less than $15 \mathrm{~nm}$ increased. Also the polycyclic aromatic hydrocarbon emissions were found to increase. [41]

Intake air fumigation is one way to make use of the advantages of ethanol in CI engines. Fumigation ethanol is introduced into the intake air, most commonly with low pressure injectors or carburettors $[5,9,-15,41]$. The maximum substitutions via fumigation have been in the range of $10-50 \%$ of the total energy output of the engine, even though the most commonly studied ethanol ratios have been $10 \%$ and $20 \%$ [9-11,41]. Thermal efficiency has been found to increase when increasing the ethanol substitution, while THC and CO emissions have also clearly increased. Soot and NOx emissions have been reported to decrease when increasing the ethanol substitution [9,10,41]. The difference between dual fuel and fumigation is that with fumigation, the diesel fuel remains the primary energy source and the secondary fuel is used mainly to control diesel combustion.

Volpato et al. [14] also achieved a high ethanol/diesel fuel ratio in their study, which focused on control system development. They studied ethanol dual fuel performance in a heavy-duty diesel engine equipped with a mechanical diesel injection pump. They found that diesel injection timing control is important if high ethanol/diesel ratios are desired [14].

Rezende et al. [15] studied an ethanol dual fuel process with a heavy-duty engine equipped with a common-rail diesel injection system and a multi-point, electrically controlled ethanol injection system. They found that ethanol dual fuel improved fuel economy and engine thermal efficiency, whereas soot, NOx and noise emissions decreased. They achieved $12-57 \%$ diesel fuel substitutions under different load conditions. The fuel cost was also taken into account as a secondary variable, while the stable combustion behaviour was the primary motivator. The engine was also installed in a vehicle operating in off-road conditions, where they achieved a $37.6 \%$ volume substitution of diesel fuel in field tests [15].

A prior study by Sarjovaara et al. [16] focused on the effects of diesel injection parameters on ethanol dual fuel combustion. The study was conducted with a heavy-duty diesel engine with manifold ethanol injectors. They found that dividing the diesel pilot injection into two separate injections had a significant effect on the cylinder pressure rise rate (PRR) and maximum ethanol share. When only one diesel injection/cycle was used, the PRR tended to be quite high and the injection timing did not have a remarkable effect on the PRR. By having a two-phase diesel injection, the PRR and maximum cylinder pressure decreased significantly and the diesel injection timings clearly affected the heat-release profiles [16]. The limit for the highest acceptable PRR was $10 \mathrm{bar} / \mathrm{CA}^{\circ}$, which was adapted from a study by Curran et al. [42], and found to be relevant here. The highest share of ethanol energy achieved was approximately $90 \%$ at high engine load [16].

Padala et al. [17] studied ethanol dual fuel combustion with a single-cylinder naturally aspired diesel engine, which had cylinder volume of 0.498 litres, and it was equipped with a common-rail injection system. They focused on the effects 
of the ethanol quantity and diesel injection timing on engine performance. The share of ethanol energy varied from 0 to $80 \%$, whereas the diesel stat of injection (SOI) varied between 13 and -1 crank angle(CA) before top dead centre (BTDC). What is notable is that they had only a single diesel injection per cycle. They found that with a fixed SOI, the engine efficiency increased by up to $10 \%$ when the ethanol share increased to $60 \%$. With higher shares, misfiring started to occur. The gain in efficiency was mainly reported in the form of decreased burn duration, but combustion phasing also played a strong role. They found that ethanol shares with greater than $20 \%$ smoke emissions were negligible, while $\mathrm{NO}_{\mathrm{x}}, \mathrm{CO}$ and THC emissions increased as the ethanol share increased [17].

The effect of the methanol fumigation on the combustion and emissions of a diesel engine was studied by Zhang et. al. [21]. In their study the methanol fumigation decreased the peak cylinder pressure at low and medium engine loads, while at high loads the peak pressure increased. The fumigation was found to increase the maximum heat release rate (HRR) and ignition delay, but it did not have significant influence on combustion duration. Particulate emissions were also found to decrease at medium and high engine loads due to the higher portion of fuel burned in the premixed mode. [21]

Geng. et al. [22] studied particulate emission reduction on methanol dual fuel diesel engine. They found that at low and medium engine loads soot emissions, as well as particulate number, decreased significantly. At high engine load soot emissions and particulate number increased. They explained the low and medium load behaviour with increased amount of fuel burned in premixed phase and the reason for opposite behaviour at high loads was explained by spontaneous combustion of methanol and less air available for diesel fuel in mixing controlled phase. [22]

Butanol port fuel injection together with exhaust gas recirculation (EGR) and their influence on diesel engine performance and emissions was studied by Chen et. al. [23]. When low EGR rate was utilized, the butanol increased the peak cylinder pressure and the peak HRR value, but there was no notable change on ignition delay. With high EGR rate the increase of butanol quantity increased ignition delay and combustion duration while the peak cylinder pressure and the peak HRR value decreased. The increase of butanol injection quantity increased THC and CO emissions and decreased the engine indicated thermal efficiency. With EGR both $\mathrm{NO}_{\mathrm{x}}$ and soot emissions decreased significantly simultaneously. [23]

In a study by Ma et al. [28], gasoline DF combustion was investigated by varying the diesel injection strategy at 0.93 MPa indicated mean effective pressure (IMEP). They studied both single and double diesel injection cases with premixed gasoline quantity between 68 to $84 \%$. They also studied the diesel fuel ratio between two diesel injections. They discovered that the injection parameter affects the dual fuel combustion process through mixture reactivity and mixture stratification. The main conclusion regarding these two properties was that the earlier the diesel fuel is injected the larger role the reactivity plays, while on the other hand later injection increases the role of stratification. With respect to the $\mathrm{NO}_{\mathrm{x}}$ emissions, the results were excellent, though the THC and CO emissions clearly increased. With a proper oxidation catalyst for THC and CO, the EURO VI emission limits were almost achieved [28].

\section{Experiments}

\subsection{Research Equipment and fuels}

The engine used in these experiments was a heavy-duty, turbo-charged diesel engine equipped with a common-rail diesel injection system and an intake manifold ethanol injection system. The specifications of the test engine are in Table 1. The intake manifold was custom made with a single intake runner for each cylinder. The ethanol injectors were assembled to intake runners upstream from the cylinder head. The original diesel fuel injection pressures and timings (including pre-injection) were utilised and only the duration of the main diesel injection was changed when E85was applied. The E85 was injected into the intake manifold sequentially with a constant pressure of $5 \mathrm{bar}(\mathrm{g})$. The test engine's charge air cooling system was disabled during the experiments.

$\mathrm{NO}_{\mathrm{x}}$ emissions were measured using an Ecophysics CLD 880 chemiluminescence analyser. A Sick Sidor multicomponent analyser was used to measure $\mathrm{O}_{2}$ with paramagnetic technology, while $\mathrm{CO}$ and $\mathrm{CO}_{2}$ were measured using a Non-Dispersive Infra-Red (NDIR) technique in the same analyser unit. Smoke emissions were measured using an AVL 
415S Smoke Meter, which measures the smoke in the filter smoke number (FSN) unit. An average of five FSN samples was used for the experiments. THC emissions were measured using a J.U.M. VE7 analyser. A Kistler 6125 uncooled piezoelectric sensor was installed on one cylinder to measure the cylinder pressure with a $0.25 \mathrm{CA}^{\circ}$ frequency. Diesel fuel consumption was measured using an AVL Fuel Meter 733, and the mass flow of E85 was measured using a Rheonik RHM03 coriolis mass flow meter. The schematic of the test apparatus is presented in figure 1.

The fuels used in this study were a commercial E85 ethanol/gasoline blend, where ethanol was produced from waste materials, and EN590 diesel fuel. E85 is commercial fuel for spark ignition engines, which has at maximum $85 \%$ of ethanol by volume and $15 \%$ of gasoline or similar hydrocarbon. The properties of the fuels used in the study are presented in table 2 .

\subsection{Measurement Programme}

The study consisted of three engine speeds and a total of 6 test cases (Table 3). In all of the test cases, the diesel injection timing values were kept the same as in the diesel reference tests. It is worth noting that in all of the diesel reference test cases, the diesel injection consisted of pilot and main injections. This feature gave good possibilities to achieve a high E85 share, as was discovered by Sarjovaara et al. in a previous study [16]. During the tests, the ethanol injection was increased until the PRR reached a value of $10 \mathrm{bar} / \mathrm{CA}^{\circ}$, which was considered as the highest acceptable value. As addition maximum E85 quantity, measurements were also done on one lower E85 quantity at each engine operation point. The BMEP in table 3 stands for brake mean effective pressure.

\subsection{Heat-Release Analysis}

Cylinder pressure indication was done using a $0.25 \mathrm{CA}^{\circ}$ frequency, and pressure values of 20 consecutive cycles were averaged to filter the cycle-to-cycle fluctuation of cylinder pressure. After this, zero phase shift Butterworth low-pass filtering was performed, with the cut-off frequency of $2000 \mathrm{~Hz}$, to filter the high frequency noise from the measurement signal. The averaged and filtered cylinder pressure data was used for net heat-release analysis, which was calculated using the following well-known equation:

$$
\frac{d Q_{n}}{d t}=\frac{\gamma}{\gamma-1} p \frac{d V}{d t}+\frac{1}{\gamma-1} V \frac{d p}{d t}
$$

where $Q_{n}$ denotes net heat-release, $t$ is time, $\gamma$ is the specific heat capacities ratio, $V$ is the volume and $p$ stands for cylinder pressure [44]. In this study the constant value of 1.35 was used for the $\gamma$.

The method selected for heat-release analysis does not take into account ethanol evaporation during the compression, blow-by or heat transfer. Despite this limitation, the HRR calculation method used here has also been widely used in the other dual fuel combustion studies $[16,17,45,46]$.

The emission results were post-processed by ISO 8178-1 standard to convert the measured volumetric based concentrations to mass based concentrations of species. [47]

\section{Results and Discussion}

The main engine operation characteristics in every test case are presented in Table 4. The E85 rate in this study was defined by the energy content and the maximum E85 ratio from 30\% to 89\%. The highest E85 rates were achieved at medium load conditions - at $1500 \mathrm{rpm}$ the medium load E85 quantity was especially very high (89\%). The fuel substitution rates were also verified, with carbon balances from the emission measurements, and the difference between fuel mass flow carbon input and exhaust gas output carbon was within 5\%. The charge air and exhaust gas pressures in Table 4 are gauge values. The E85 rate did not have a strong effect on the charge air pressure. At the every operation point, the charge air pressure variation was in the range of 0.1 bar with different E85 rates. The behaviour of the exhaust gas pressures was very similar. There were only minor changes in the values when the E85 rate was varied. At every operation point except the $1000 \mathrm{rpm}$ case, the increase in the $\mathrm{E} 85$ rate lowered the exhaust gas temperatures. The effect was in the range of 15 to $30{ }^{\circ} \mathrm{C}$, and the effect was strongest at high engine loads and at the highest E85 rates. The lambda values in this study stands for total lambda calculated from the measured charge air and fuel mass flows. At low and medium load operation points at $1500 \mathrm{rpm}$, lambda decreased as the E85 rate increased, and the trend was 
especially clear in the low-load case. In the $1500 \mathrm{rpm}$ high-load case and $2300 \mathrm{rpm}$ cases, the trend was the opposite lambda increased slightly as the E85 rates increased. At $1000 \mathrm{rpm}$, lambda behaviour is nonlinear. At the lower E85 rate, lambda increased, but when the rate was increased further, lambda decreased below the value of the diesel reference case.

The diesel injection timing parameters are also presented in Table 4. The diesel injection parameters, except the main injection duration, were the same as in the $0 \%$ E85 case at every operation point.

\subsection{Cylinder Pressure and Heat Release rate}

The cylinder pressures and HRR at $1000 \mathrm{rpm}$ and 6.5 bar BMEP are shown in Figure 2. The differences in cylinder pressures and heat releases were rather small when comparing the diesel reference and two different shares of E85. With E85, the peak pressures and maximum heat release values were slightly lower than in the diesel reference case, and there was no clear difference between the two E85 rates.

At $1500 \mathrm{rpm}$ and 3.4 bar BMEP, the differences (Figure 3) were more obvious than at $1000 \mathrm{rpm}$. It can be seen that ignition delay tended to increase with E85. The ignition delays are presented and discussed in more detail later in this paper. With the $28 \%$ E85 rate, the heat release was strong before TDC, and it maintained almost constantly until $6 \mathrm{CA}^{\circ}$ ATDC, when it started to increase significantly. The heat release with the $49 \%$ E85 rate was more similar to the diesel reference case. In that case, the BTDC peak was slightly later than in the reference case, and the second peak ATDC reached its maximum value earlier than in the reference case. This second peak was also slightly lower than in the reference case. E85 also increased the combustion duration.

Figure 4 presents the cylinder pressures and heat release at 1500rpm and 6.8 bar BMEP. At this load, the 10 bar/CA ${ }^{\circ}$ PRR limit was not the limitation for the maximum E85 rate. The limitation came from the engine control system, which had engine speed as input, and it was kept constant by decreasing the main injection as the E85 rate was increased. When the total amount of diesel reached a certain minimum level, the control system started to disable the pre-injection. This caused an undesired operation in these studies, since the diesel injections would not have been comparable to the way it was designed.

In both E85 cases at this engine operation point the cylinder pressure was lower before combustion than in reference case. Notable is that there was no difference in charge air pressures (table 4), so lower compression pressure could be due to the large amount of E85 evaporated in cylinder during the compression stroke. E85 increased ignition delay and decreased the combustion duration. In $69 \%$ of the E85 case, HRR had three peaks, while $89 \%$ of the E85 case had only two peaks. The three peaks at the lower E85 rate are most likely caused by the pre-injection diesel combustion, the main injection diesel fuel combustion, and the flame front combustion of the remaining E85, which did not burn during the first two phases of combustion. With the higher E85 rate, the second phase (main injection diesel phase) seems to be missing, and the time between first and last peaks is longer. The explanation for this behaviour could be the leaner mixture after the main injection, due to the smaller injected diesel fuel amount and the higher amount of pre-mixed E85, which decreased the reaction speed of the combustion. After the first peak, the HRR had a rather constant value, which indicated on-going combustion reactions, but the temperature inside the cylinder was not high enough to enable a rapid start of the flame front combustion of the remaining premixed E85/diesel blend.

The highest load at 1500rpm was 11.9bar BMEP. At this load, the E85 decreased the ignition delay and caused strong heat release peak BTDC, especially with a higher E85 rate (Figure 5). The reason for the behaviour could be the autoignition of E85. With a higher E85 rate (34\%), the compression pressure was lower than in two other cases at this engine load. As with the 6.8 bar BMEP load, this could also indicate a significant amount of E85 evaporated during the compression stroke. The combustion duration was also shorter with E85 at this engine operation point.

Figure 6 represents the cylinder pressures and heat releases at 2300rpm and the 5.1bar BMEP operation point. At this load case, the higher E85 rate decreased the compression pressure, while there were no differences in compression pressures between the reference case and the lower E85 rate case. The differences in ignition delays between cases were small, but the combustion durations in the E85 cases were clearly shorter. At this engine operation point, both E85 cases had three heat release peaks, indicating pre-injection and main injection diffusion combustion and premixed flame front 
combustion of the remaining E85. Also notable was that with the higher E85 rate, more E85 burned during the second peak than with the lower E85 rate, which had a higher HRR peak at the last combustion phase.

The 8.5 bar BMEP case was the highest engine load tested at $2300 \mathrm{rpm}$; the cylinder pressures and heat releases are shown in Figure 7. At this load, the compression pressure decreased slightly with the highest E85 rate. As at the lower load at $2300 \mathrm{rpm}$, there were no significant differences in ignition delays, but the combustion durations were clearly shorter with E85. At this load case, the heat releases had two peaks, indicating that all the fuel was burned during the pre-injection and main injection combustion phases. The high HRR peak with E85 at the pre-injection phase indicated that most of the E85 was burned during this phase.

The ignition delays are presented in Figure 8. The figure shows that E85 increased ignition delays, except in the 11.9 bar BMEP at $1500 \mathrm{pm}$ case, where the early ignition could be explained by auto-ignition. Though there can be seen a trend of increasing ignition delay as the E85 rate increased, the differences were at maximum in the range of $1 \mathrm{CA}^{\circ}$.

\subsection{Emissions}

The specific THC emission increased significantly at the lower loads, indicating uncompleted combustion due to the low cylinder temperatures and the lean mixture (Table 4). With the high and medium loads, the THC emissions also increased, but the slope was clearly lower, especially when the E85 rate was below $70 \%$. The specific THC emissions were lowest at the highest loads, where most of the THC was caused by fuel trapped in the cylinder crevices and intake injected E85 flow in the exhaust system during the valve overlap. The valve overlap can be the THC emission source if the charge air pressure is higher than the exhaust pressure, which was the case at the $1500 \mathrm{rpm}$ high load operation point.

The injection of E85 increased CO emissions at every engine operation point (Figure 10). This indicates uncompleted combustion, since the source for increasing $\mathrm{CO}$ is the freezing of the chemical combustion reactions before $\mathrm{CO}$ is further oxidized to $\mathrm{CO}_{2}$. As with THC emissions, with $\mathrm{CO}$ the low loads with very lean mixtures were the cases with the highest concentrations. It was also interesting that the $2300 \mathrm{rpm}$ and 5.1 bar BMEP case has a high CO emission, while the THC emissions were relatively low and consistent with other medium and high load cases. There were also some differences in $\mathrm{CO}$ trends between medium and high loads, when compared to THC emission behaviour. The CO emission trend in the $1500 \mathrm{rpm}$ and 6.8 bar BMEP case was very linear, while in the THC emission there was clearly a nonlinear trend. Also, the difference between CO emissions in the $1500 \mathrm{rpm}$ and $2300 \mathrm{rpm}$ high load cases was bigger than with THC, where the specific emissions were almost similar in these two cases.

The specific $\mathrm{NO}_{\mathrm{x}}$ trends, shown in Figure 11, can be divided into two groups. In two high load cases, the E85 increased the $\mathrm{NO}_{\mathrm{x}}$ emissions slightly, while in the rest of the engine operation points the trends were decreasing. With these cases with decreasing $\mathrm{NO}_{\mathrm{x}}$ emissions, the trends were rather consistent and had similar slopes, except in the high E85 rate case at $1500 \mathrm{rpm}$ and 6.8 bar BMEP. At that load, the $\mathrm{NO}_{\mathrm{x}}$ trend was consistent with other medium and low load cases until an E85 rate of $69 \%$. But when the $\mathrm{E} 85$ rate was further increased, the $\mathrm{NO}_{\mathrm{x}}$ value decreased with a higher slope. A similar nonlinear trend at this load was also seen with THC emissions. At this specific load, the $\mathrm{NO}_{\mathrm{x}}$ emission decreased to one-third of the reference value.

The smoke emissions in this study were measured in FSN. The results are shown in Figure 12. The smoke emissions were low in every test case $(<0.15 \mathrm{FSN})$. At some loads, there was a decreasing trend, but the differences were rather small, except in the $1500 \mathrm{rpm}$ and 6.8 bar BMEP case, where there was practically no measurable smoke at the highest E85 rate.

\subsection{Efficiency}

The increase in THC and CO emission indicated uncompleted combustion. This can be also seen in the combustion efficiency trends presented in Figure 13. The combustion efficiency was calculated from the emission data [44]. The results were consistent with emissions, especially with specific THC results. It can be seen that combustion efficiency decreased most in the low load cases and the case where the E85 rate was highest. At the low loads, the reasons were most likely the lean mixture, the low in-cylinder temperature and the small amount of injected diesel fuel, which might have caused cold regions inside the cylinder during the combustion. The slope of the highest E85 rate case, $1500 \mathrm{rpm}$ 
and 6.8 bar BMEP, was well in line with other medium and high load cases, but the absolute efficiency drop was greater, since the E85 substitution rate was significantly higher at this load.

The brake thermal efficiency (BTE) results are in Figure 14. The BTE trends varied clearly between the engine operation points. The BTE increased in two high load cases, while it was constant or decreased at other loads. The explanation for this inconsistent behaviour could be the combustion phasing, which was not optimized in this study. In other words, the BTE could be improved by adjusting the diesel injection timing parameters to optimize the positions of the heat release peaks. This would naturally also affect the PRR values and the maximum acceptable E85 rates.

The mechanical efficiency values are presented in Figure 15. Only the $1500 \mathrm{rpm}$ and 3.4 bar BMEP case has a decreasing trend, while other cases have an increasing mechanical efficiency. This behaviour was caused by variation in the gross indicated mean effective pressure (IMEP360) between different E85 rates.

The two $2300 \mathrm{rpm}$ cases had an increasing trend in volumetric efficiencies (Figure 18). In all other cases, the volumetric efficiencies were constant. This could be due to the cooling effect of E85 evaporated during the intake stroke. The $2300 \mathrm{rpm}$ cases had the highest charge air temperatures (Table 4), which could have enabled rapid evaporation during the induction. The compression pressure behaviour in these cases (figures 6 and 7) indicates that only a small amount of E85 is evaporated during the compression stroke, which supports the assumption of evaporation before the compression stroke. The volumetric efficiencies were defined based on the atmospheric condition in this study.

\section{Conclusions}

The maximum E85 energy shares achieved here, limited by the PRR and minimum diesel injection quantity enabling two-phase injection, varied from $30 \%$ to $89 \%$. The diesel injection timing parameters were kept similar to those in the diesel reference tests, which limited the maximum shares achieved at certain loads. In all six engine operation points, the $\mathrm{CO}$ and THC emissions clearly increased as E85 was introduced, but in most cases the $\mathrm{NO}_{\mathrm{x}}$ emissions decreased. Soot emissions were relatively low in all cases.

The highest portion of E85 was achieved under a medium load condition at $1500 \mathrm{rpm}$, and the high load conditions were especially challenging due to the high PRR values and the auto-ignition behaviour of the pre-mixed fuel. In most cases, the ignition delay increased slightly and the duration of combustion decreased as the E85 share increased.

The combustion efficiency decreased at all loads as the E85 rate increased, due to the higher concentration of $\mathrm{CO}$ and THC emissions. The brake thermal efficiency varied from point to point. The BTE increased in two high load cases, while it was constant or decreased at other loads since the engine was not optimized for E85 dual fuel operation. This meant that the combustion phasing was not beneficial in some cases.

The results presented in this paper show that an E85 blend has potential as a dual fuel option, but it clearly requires further investigation and more development to widen the load area where high substitution rates can be achieved, especially for high loads. The future plans of the authors are to study the effect of the charge air temperature on dual fuel combustion.

\section{Acknowledgements}

Support for this project was provided by ST1 Oy, Merenkulun säätiö and Henry Fordin Säätiö. The research was performed at Department of energy technology, Aalto University, Finland.

\section{References}

[1] International Energy Agency, World Energy Outlook 2010, OECD/IEA, Paris; 2010. 
[2] U.S. Energy Information Administration, International Energy Outlook 2010, DOE/EIA-0484(2010), Washington; 2010.

[3] International Energy Agency, Technology Roadmap Biofuels for Transport, OECD/IEA, Paris; 2011.

[4] European Union, DIRECTIVE 2009/28/EC, EU, 23.4.2009.

[5] Owen K, Coley T, Automotive Fuels Handbook, $2^{\text {nd }}$ edition, SAE International, ISBN 1-56091-589-7; 1995.

[6] Elliot MA, Davis RF, Dual-Fuel Combustion in Diesel Engines, Industrial and Engineering Chemistry 1951;43:2854-2864.

[7] Mokhatab S, Mak JY, Valappil JV, Wood DA, Handbook of Liquefied Natural Gas, Gulf Publishing, ISBN 978-012-404585-9; 2014.

[8] European Union, DIRECTIVE 2012/33/EC, EU, 21.11.2012.

[9] Abu-Qudais M, Haddad O, Qudaisat M, The effect of alcohol fumigation on diesel engine performance and emissions, Energy Conversion \& Management 2000;41:389-399.

[10] Ottikkutti P, Van Gerpen J, Cui KR, Multizone Modeling of a Fumigated Diesel Engine, SAE Technical Paper Series; 910076: 1991.

[11] Surawski NC, Miljevic B, Roberts BA, Modini RL, Situ R, Brown RJ , Bottle SE, Ristovski ZD, Particle Emissions, Volatility, and Toxicity from an Ethanol Fumigated Compression Ignition Engine, Environ. Sci. Technol. 2010;44:229-235.

[12] Bodisco T, Brown RJ, Inter-Cycle Variability of In-Cylinder Pressure Parameters in an Ethanol Fumigated Common Rail Diesel Engine, Energy 2013;52:55-56.

[13] Chauhan BS, Kumar N, Pal SS, Jun YD, Experimental Studies on Fumigation of Ethanol in a Small Capacity Diesel Engine, Energy 2011;36:1030-1038.

[14] Volpato O, Theunissen F, Pimenta V, Vergineli L, Control System for Diesel-Ethanol Engines, SAE Technical Paper Series; 2010-36-0161: 2010.

[15] Rezende H, Furquim R, Odlevak E, Cruz E, Elizardo R, Salles E, Molgori S, Ethanol Diesel Truck Engine, SAE Technical Paper Series; 2011-36-0319: 2011.

[16] Sarjovaara T, Alantie J, Larmi M, Ethanol Dual-Fuel Combustion Concept on Heavy Duty Engine, Energy 2013;63:76-85.

[17] Padala S, Woo C, Kook S, Hawkes ER, Ethanol Utilisation in a Diesel Engine Using Dual-Fuelling Technology, Fuel 2013;109:597-607.

[18] Zhang ZH, Cheung CS, Chan TL, Yao CD, Emission reduction from diesel engine using fumigation methanol and diesel oxidation catalyst, Science of the Total Environment 2009;407;4497-4505.

[19] Uduyakumar R, Sundaram S, Sivakumar K, Engine Performance and Exhaust Characteristics of Dual Fuel Operation in DI Diesel Engine with Methanol, SAE Technical Paper Series; 2004-01-0096: 2004.

[20] Raj CS, Arul S, Senthilvelan S, Some Comparative Performance and Emission Studies on DI Diesel Engine Fumigated with Methanol and Methyl Ethyl Ketone Using Microprocessor-Controlled Fumigator, The Open Fuels \& Energy Science Journal 2008;1:74-78.

[21] Zhang ZH, Cheung CS, Yao CD, Influence of Fumigation Methanol in the Combustion and Particulate Emissions of a Diesel Engine, Fuel 2013;111:442-448. 
[22] Geng P, Yao C, Wei L, Liu J, Wang Q, Pan W, Wang J, Reduction of PM Emissions from a Heavy-Duty Diesel Engine with Diesel/Methanol Dual Fuel, Fuel 2014;123:1-11.

[23] Chen Z, Liu J, Wu Z, Lee C, Effects of Port Fuel Injection (PFI) of n-Butanol and EGR on Combustion and Emissions of a Direct Injection Diesel Engine, Energy Conversion and Management 2013;76:725-731.

[24] Varde KS, Propane Fumigation in a Direct Injection Type Diesel Engine, SAE Technical Paper Series; 831354: 1983.

[25] Saanum I, Bysveen M, Hustad JE, Study of Particulate Matter-, NOx- and Hydrocarbon Emissions from a Diesel Engine Fueled with Diesel Oil and Biodiesel with Fumigation of Hydrogen, Methane and Propane, SAE Technical Paper Series; 2008-01-1809: 2008.

[26] Tira HS, Herreros JM, Tsolakis A, Wyszynski ML, Characteristics of LPG-Diesel Dual Fuelled Engine Operated with Rapeseed Methyl Ester and Gas-to-Liquid Diesel Fuels, Energy 2012;47:620-629.

[27] Sahin Z, Durgun O, High speed direct injection (DI) light-fuel (gasoline) fumigated vehicle diesel engine, Fuel 2007;86:388-399.

[28] Ma S, Zheng Z, Liu H, Zhang Q, Yao M, Experimental Investigation of the Effects of Diesel Injection Strategy on Gasoline/Diesel Dual-Fuel Combustion, Applied Energy 2013;109:202-212.

[29] Jeuland N, Montagne X, Gautrot X, Potentiality of Ethanol as a Fuel for Dedicated Engine, Oil \& Gas Science and Technology - Rev. IFP, Vol. 59, No. 6, pp. 559-570, 2004.

[30] Chen L, Stone R, Richardson D, A Study of Mixture Preparation and PM Emissions Using a Direct Injection Engine Fuelled with Stoichiometric Gasoline/Ethanol Blends, Fuel 2012;96:120-130.

[31] Türköz N, Erkus B, Karamangil MI, Sürmen A, Arslanoglu N, Experimental Investigation of the Effect of E85 on Engine Performance and Emissions Under Various Ignition Timings, Fuel 2014;115:826-832.

[32] Splitter D, Kokjohn S, Rein K, Hanson R, Sanders S, Reitz R, An Optical Investigation of Ignition Processes in Fuel Reactivity Controlled PCCI Combustion, SAE Technical Paper Series; 2010-01-0345: 2010.

[33] Curran S, Hanson R, Wagner R, Effect of E85 on RCCI Performance and Emissions on a Multi-Cylinder LightDuty Diesel Engine, SAE Technical Paper Series; 2012-01-0376: 2011.

[34] Lei J, Bi Y, Shen L, Performance and Emission Characteristics of Diesel Engine Fueled with Ethanol-Diesel Blends in Different Altitude Regions, Journal of Biomedicine and Biotechnology, 2011;417421:1-10.

[35] Lee WJ, Liu YC, Mwangi FK, Chen WH, Lin SL, Fukushima Y, Liao CN, Wang LC, Assessment of Energy Performance and Air Pollutant Emissions in a Diesel Engine Generator Fueled with Water-Containing EthanolBiodiesel-Diesel Blend of Fuels, Energy 2011;36:5591-5599.

[36] Silveira MB, do Carmo FR, Santiago-Aguiar RS, de Sant'Ana HB, Ab-diesel: Liquid-Liquid Equilibrium and Volumetric Transport Properties, Fuel 2014;119:292-300.

[37] Beatrice C, Napolitano P, Guido C, Injection Parameter Optimization by DoE of a Light-Duty Diesel Engine Fed by Bio-Ethanol/RME/Diesel Blend, Applied Energy 2014;113:373-384.

[38] Zhu H, Bohac SV, Nakashima K, Hagen LM, Huang Z, Assanis DN, Effect of Biodiesel and Ethanol on Load Limits of High-Efficiency Premixed Low-Temperature Combustion in a Diesel Engine, Fuel 2013;106:773-778.

[39] Sayin C, Ozsezen, Canakci M, The Influence of Operationg Parameters on the Performance and Emissions of a DI Diesel Engine Using Methanol-Blended-Diesel Fuel, Fuel 2010;89:1407-1414. 
[40] Yilmaz N, Vigil FM, Benalil K, Davis SM, Calva A, Effetc of Biodiesel-Butanol Fuel Blends on Emissions and Performance Characteristics of a Diesel Engine, Fuel 2017;135:46-50.

[41] Zhang ZH, Balasubramanian R, Influence of Butanol-Diesel Blends on Particulate Emission of a Non-Road Diesel Engine, Fuel 2014;118:130-136.

[42] Tsang KS, Zhang ZH, Cheung CS, Chan TL, Reducing Emissions of a Diesel Engine Using Fumigation Ethanol and a Diesel Oxidation Catalyst, Energy Fuels 2010;24:6156-6165.

[43] Curran SJ, Hanson RM, Wagner RM, Reactivity controlled compression ignition combustion on a multicylinder light-duty diesel engine, International J. of Engine Research 2012;13:216-225.

[44] Heywood JB, Internal Combustion Engine Fundamentals, McGrawn-Hill, Singapore, ISBN 0-07-100499-8; 1988.

[45] Mack JH, Aceves SM, Dibble RW, Demonstrating Direct Use of Wet Ethanol in a Homogenous Charge Compression Ignition (HCCI) Engine, Energy 2008;34:782-787.

[46] Soloiu V, Duggan M, Harp S, Vleck B, Williams D, PFI (Port Fuel Ignition) of n-Butanol and Direct Injection of Biodiesel to Attain LTC (Low-Temperature Combustion) for Low-Emission Idling in a Compression Engine, Energy 2013;52:143-154.

[47] European Committee for Standardization, Reciprocating internal combustion engines - Exhaust emission measurement - Part 1: Test-bed measurement of gaseous and particulate exhaust emissions (IS0 8176-1:1996), Brussels, 1996. 
Table

Table 1

\begin{tabular}{ll}
\hline Displaced volume & 7.4 Litres \\
Number of cylinders & 6 \\
Rated Power & $120 \mathrm{~kW}$ \\
Compression ratio & $16.5: 1$ \\
Number of Valves per cylinder & 2 \\
Rated speed & $2300 \mathrm{rpm}$ \\
External EGR & No \\
Exhaust gas after-treatment & No \\
\hline
\end{tabular}

Displaced volume

Exhaust gas after-treatment
7.4 Litres

$120 \mathrm{~kW}$

$2300 \mathrm{rpm}$

No 


\begin{tabular}{lccc} 
& & Diesel EN590 & E85 \\
\hline Density & $\mathrm{kg} / \mathrm{m}^{3}$ & 840 & 785 \\
Cetane number & - & 53 & - \\
Octane number & - & - & 105 \\
Carbon & $\mathrm{wt}-\%$ & 85.8 & 55.4 \\
Hydrogen & $\mathrm{wt}-\%$ & 13.6 & 13.2 \\
Oxygen & $\mathrm{wt}-\%$ & - & 31.4 \\
Stoichiometric air-fuel ratio & - & 14.5 & 9.5 \\
95\% evaporated & ${ }^{\circ} \mathrm{C}$ & 340 & - \\
Lower heating value & $\mathrm{MJ} / \mathrm{kg}$ & 43.2 & 28.7 \\
\hline
\end{tabular}




\section{Table 3}

\begin{tabular}{cccc}
$\begin{array}{c}n \\
\text { rpm }\end{array}$ & $\begin{array}{c}\text { load } \\
\text { Nm }\end{array}$ & $\begin{array}{c}\text { BMEP } \\
\text { bar }\end{array}$ & $\begin{array}{c}\text { Power } \\
\text { Kw }\end{array}$ \\
\hline 1000 & 150 & 2.5 & 16 \\
1500 & 200 & 3.4 & 31 \\
1500 & 400 & 6.8 & 63 \\
1500 & 700 & 11.9 & 110 \\
2300 & 300 & 5.1 & 72 \\
2300 & 500 & 8.5 & 120 \\
\hline
\end{tabular}




\begin{tabular}{|c|c|c|c|c|c|c|c|c|c|c|c|}
\hline$=5$ & $\sum_{m}^{i}$ & 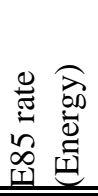 & 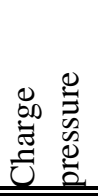 & 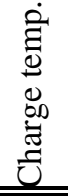 & 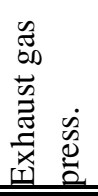 & 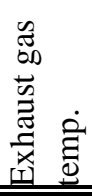 & 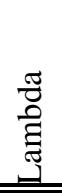 & $\begin{array}{l}\overline{0} \\
\vdots \\
\dot{\Xi} \\
\dot{0} \\
\end{array}$ & $\begin{array}{l}\dot{\Xi} \\
\dot{\Xi} \\
\dot{\Xi} \\
\dot{\Xi}\end{array}$ & 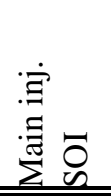 & 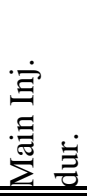 \\
\hline $\mathrm{rpm}$ & bar & $\%$ & bar & ${ }^{\circ} \mathrm{C}$ & bar & ${ }^{\circ} \mathrm{C}$ & - & $\begin{array}{c}\mathrm{CA}^{\circ} \\
\mathrm{BTDC}\end{array}$ & $\mathrm{CA}^{\circ}$ & $\begin{array}{c}\mathrm{CA}^{\circ} \\
\mathrm{BTDC}\end{array}$ & $\mathrm{CA}^{\circ}$ \\
\hline \multirow[t]{3}{*}{1000} & 2.5 & 0 & 0.1 & 34 & 0.1 & 207 & 4.3 & 12.3 & 1.6 & 7.0 & 3.2 \\
\hline & 2.5 & 19 & 0.1 & 33 & 0.1 & 206 & 4.5 & 12.3 & 1.6 & 7.0 & 3.1 \\
\hline & 2.5 & 37 & 0.1 & 33 & 0.1 & 212 & 4.0 & 12.3 & 1.6 & 7.0 & 2.9 \\
\hline \multirow[t]{9}{*}{1500} & 3.4 & 0 & 0.2 & 51 & 3.0 & 270 & 4.0 & 15.3 & 2.4 & 7.3 & 4.9 \\
\hline & 3.4 & 28 & 0.3 & 51 & 3.1 & 265 & 3.7 & 15.3 & 2.4 & 7.3 & 4.6 \\
\hline & 3.4 & 49 & 0.3 & 52 & 3.2 & 265 & 3.4 & 15.3 & 2.4 & 7.3 & 4.0 \\
\hline & 6.8 & 0 & 0.5 & 71 & 0.5 & 381 & 2.6 & 15.5 & 2.4 & 7.5 & 7.2 \\
\hline & 6.8 & 69 & 0.4 & 70 & 0.4 & 352 & 2.5 & 15.5 & 2.4 & 7.5 & 3.9 \\
\hline & 6.8 & 89 & 0.5 & 70 & 0.4 & 352 & 2.4 & 15.5 & 2.4 & 7.5 & 2.7 \\
\hline & 11.9 & 0 & 1.0 & 111 & 0.7 & 533 & 1.8 & 15.4 & 2.7 & 6.5 & 9.9 \\
\hline & 11.9 & 17 & 0.9 & 112 & 0.6 & 520 & 1.8 & 15.4 & 2.7 & 6.5 & 7.5 \\
\hline & 11.9 & 34 & 0.9 & 108 & 0.6 & 502 & 1.9 & 15.4 & 2.7 & 6.5 & 6.4 \\
\hline \multirow[t]{6}{*}{2300} & 5.1 & 0 & 1.0 & 114 & 1.1 & 377 & 3.3 & 24.0 & 3.5 & 12.1 & 8.6 \\
\hline & 5.1 & 29 & 1.0 & 112 & 1.1 & 366 & 3.3 & 24.0 & 3.5 & 12.1 & 7.2 \\
\hline & 5.1 & 47 & 0.9 & 110 & 1.1 & 358 & 3.4 & 24.0 & 3.5 & 12.1 & 6.6 \\
\hline & 8.5 & 0 & 1.1 & 124 & 1.3 & 512 & 2.5 & 23.5 & 3.3 & 12.1 & 11.3 \\
\hline & 8.5 & 17 & 1.1 & 125 & 1.3 & 496 & 2.6 & 23.5 & 3.3 & 12.1 & 9.6 \\
\hline & 8.5 & 30 & 1.1 & 124 & 1.3 & 482 & 2.7 & 23.5 & 3.3 & 12.1 & 8.6 \\
\hline
\end{tabular}


Figure 1

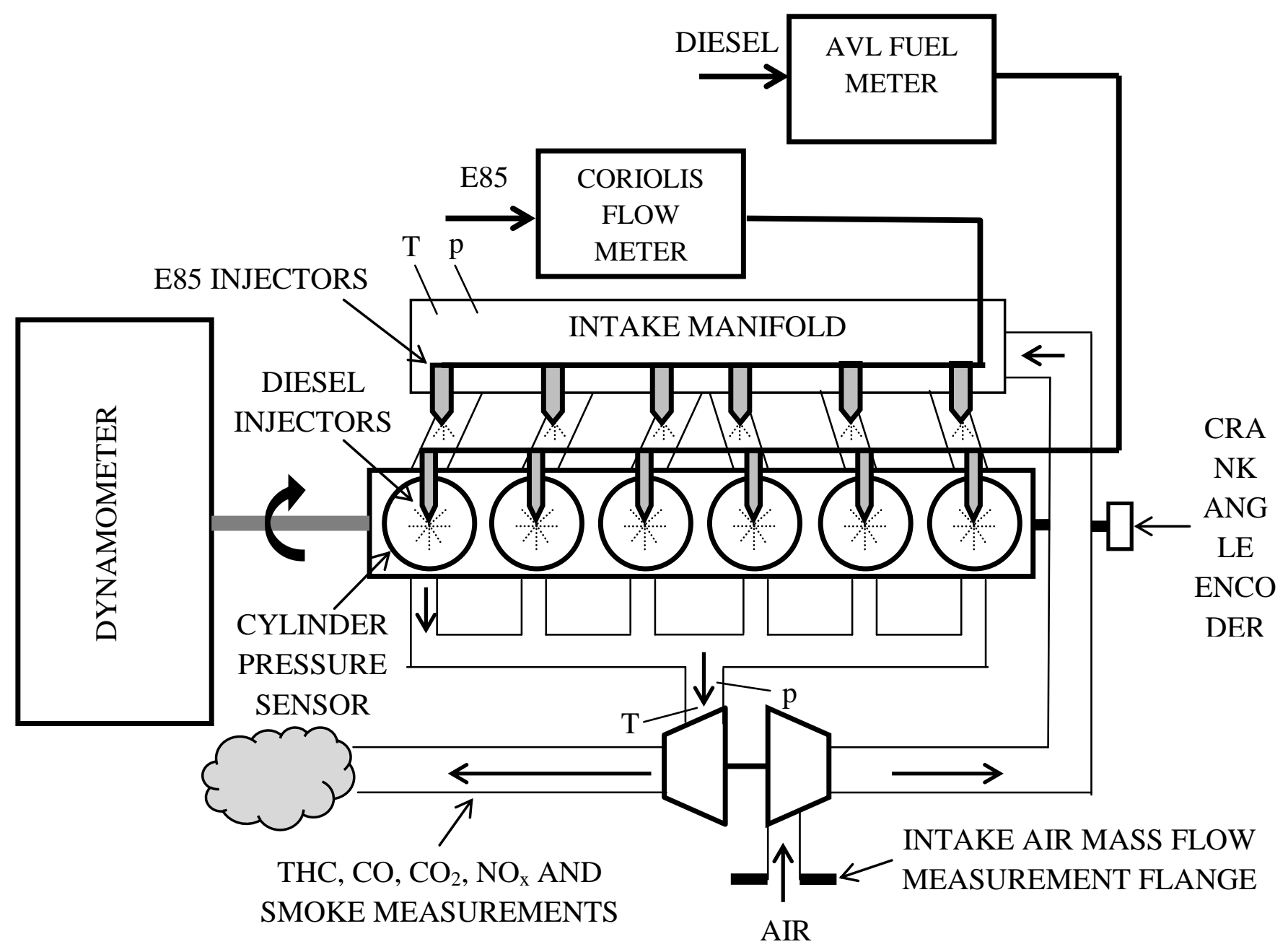




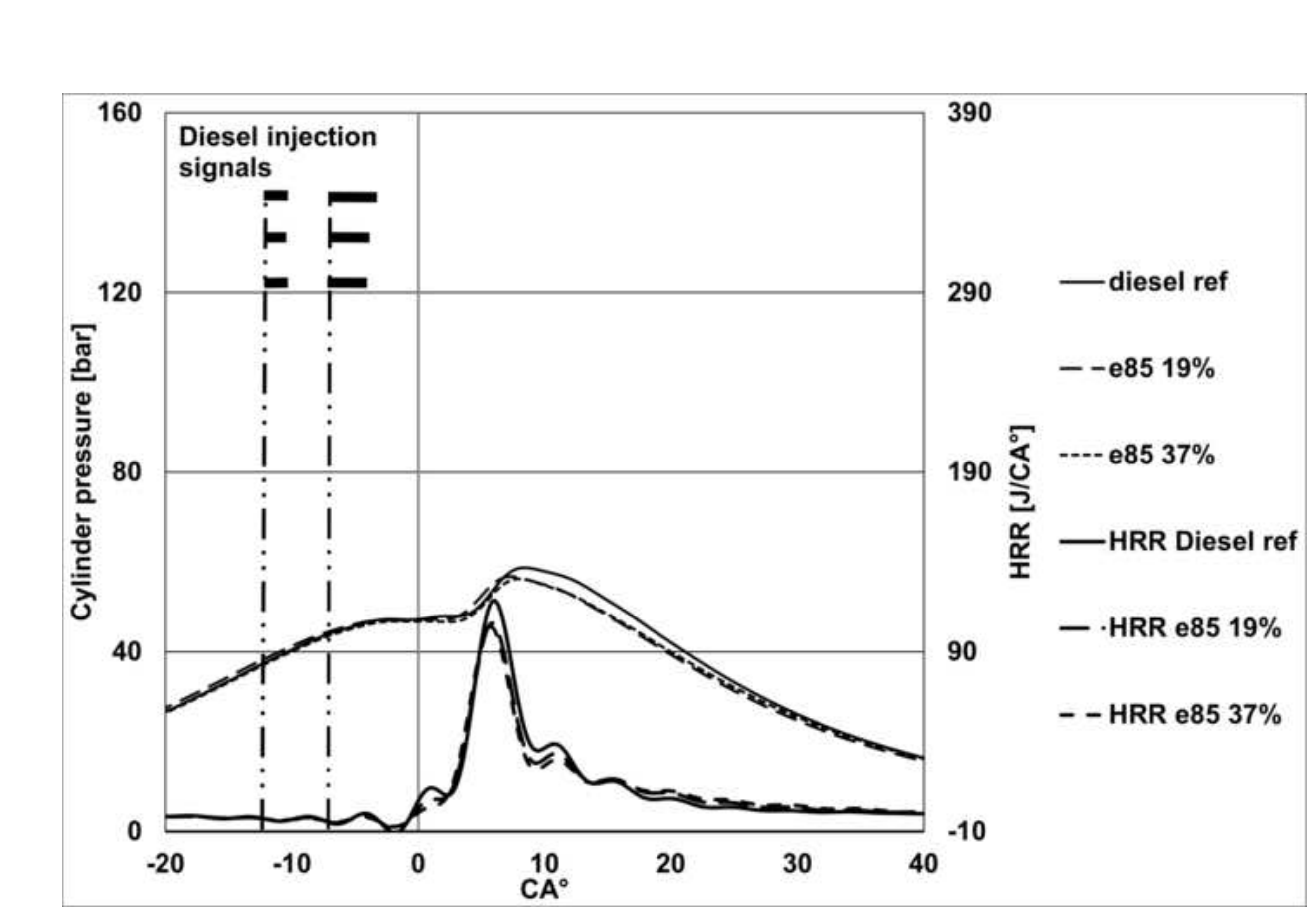

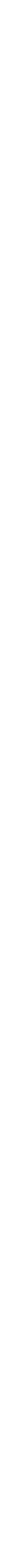

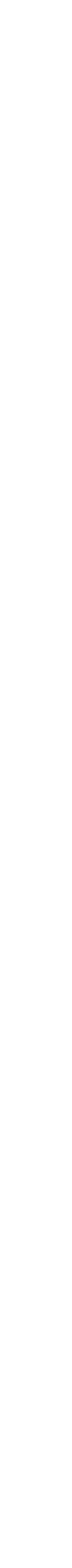




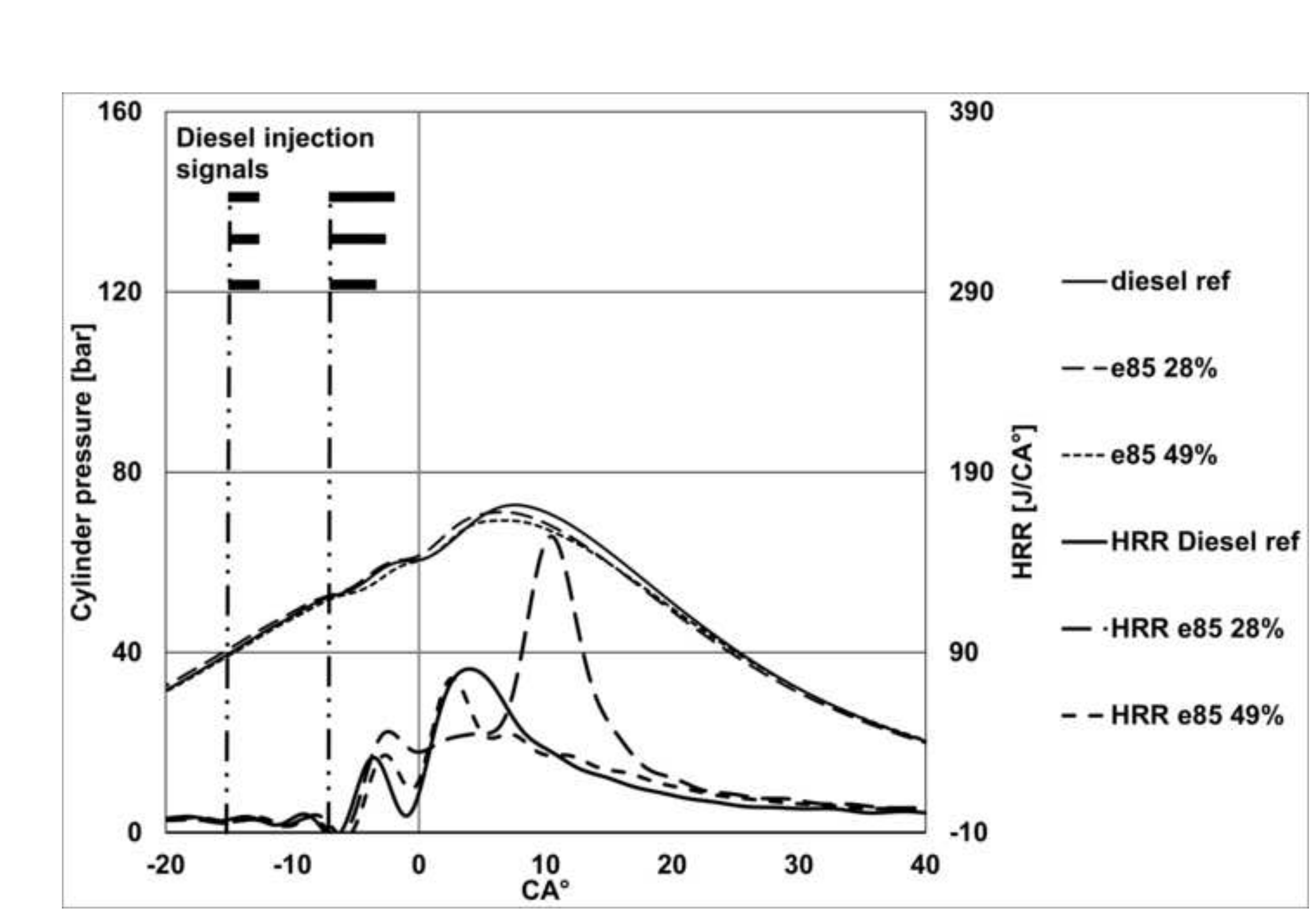




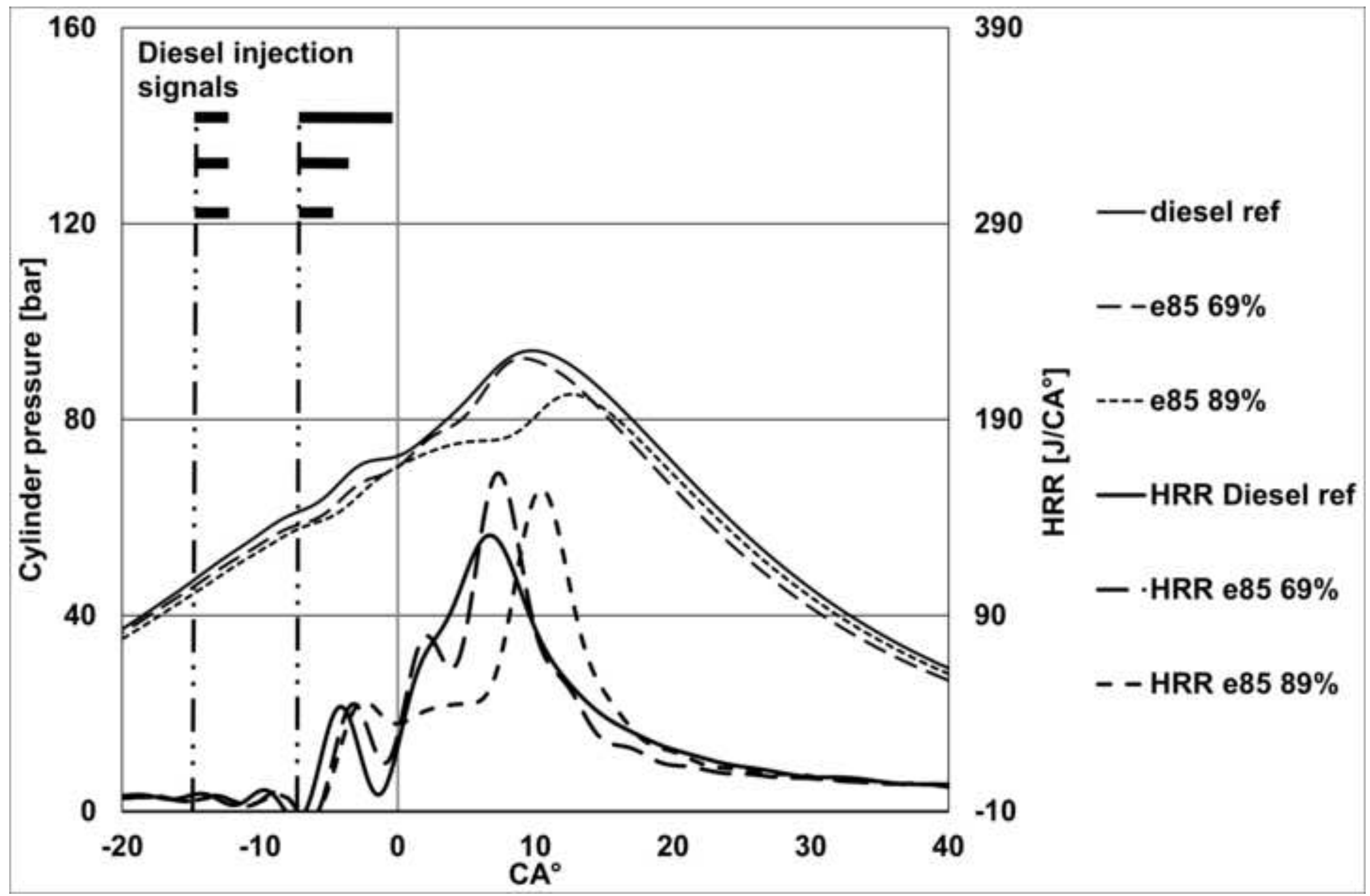




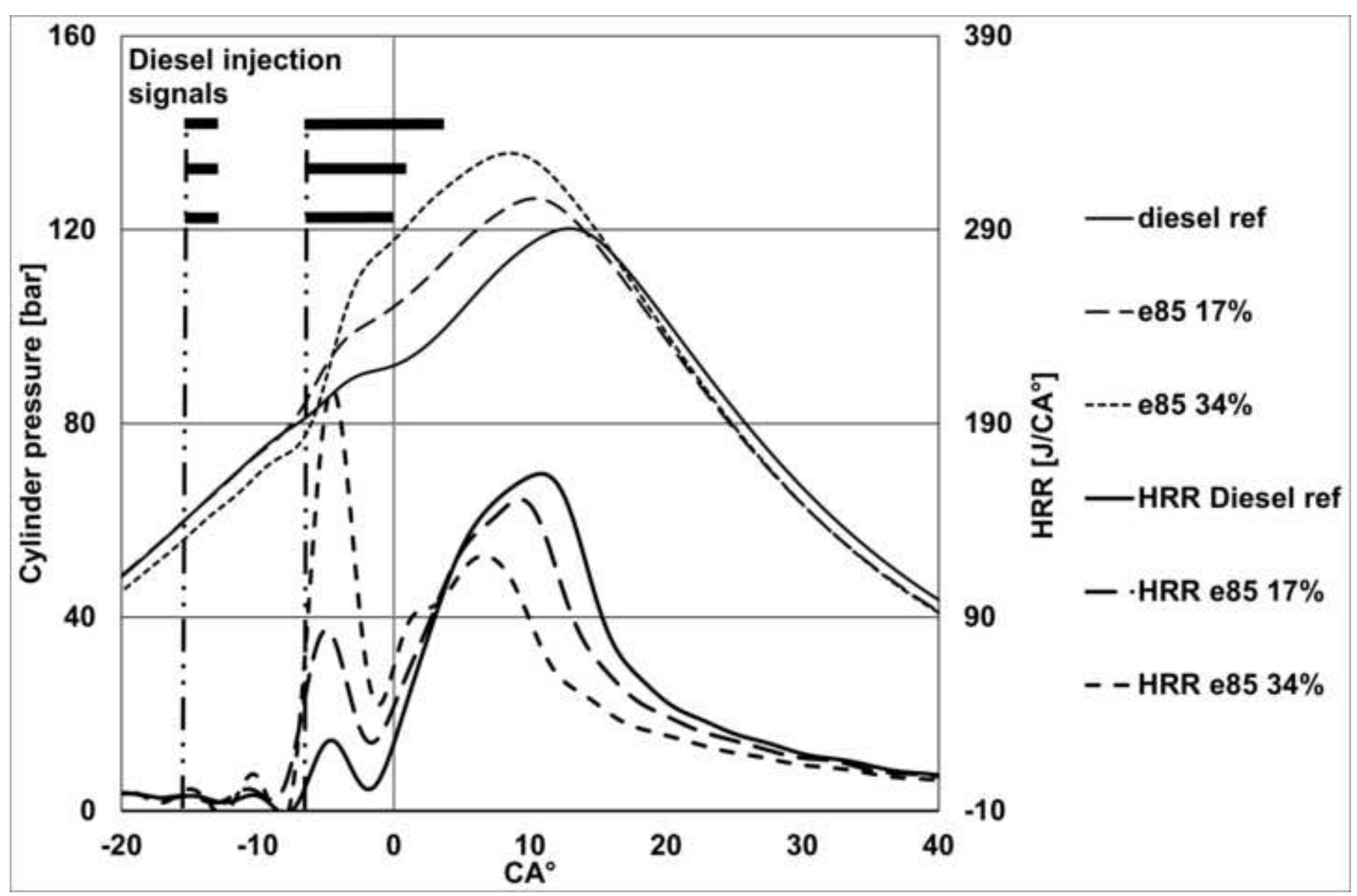




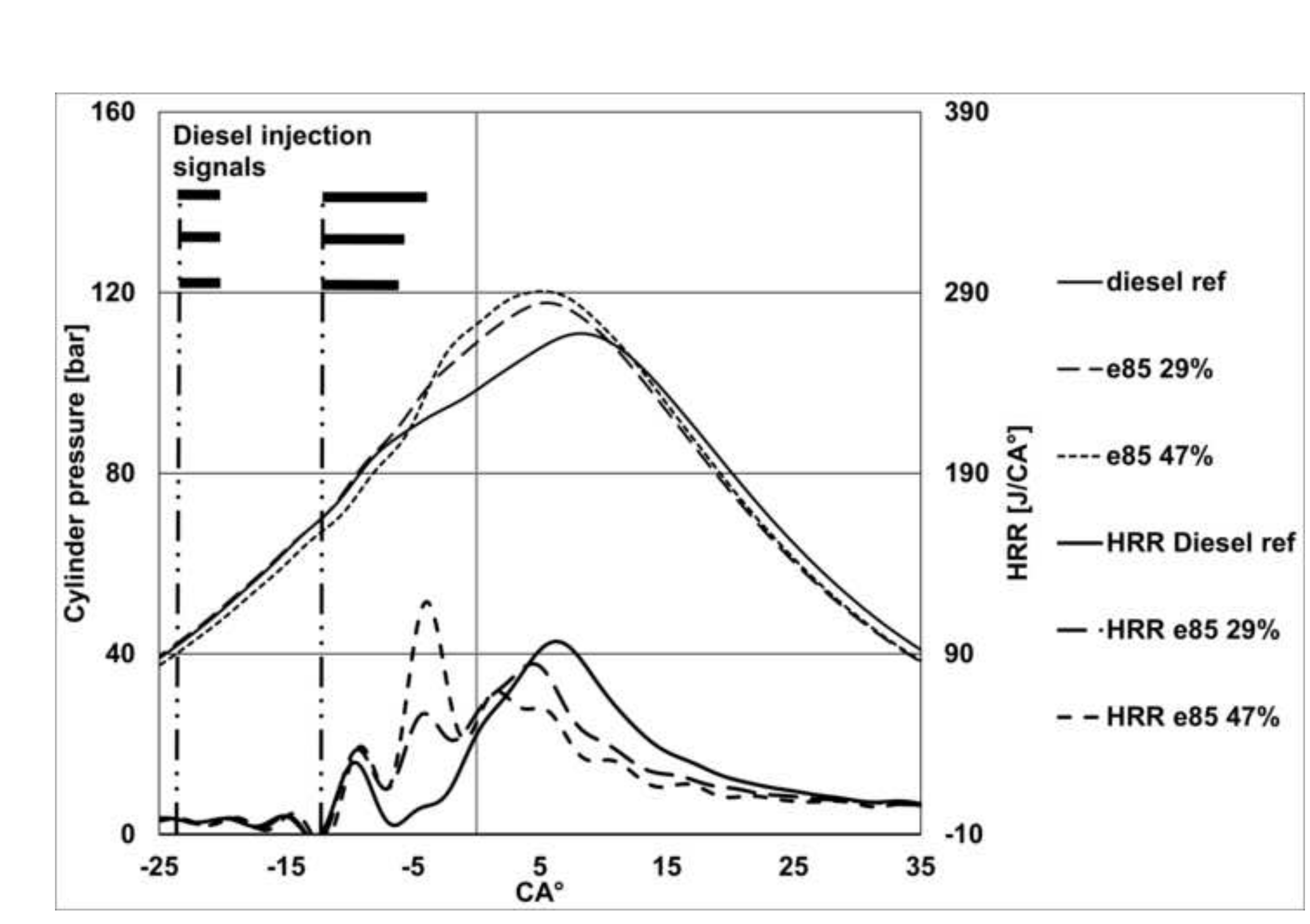




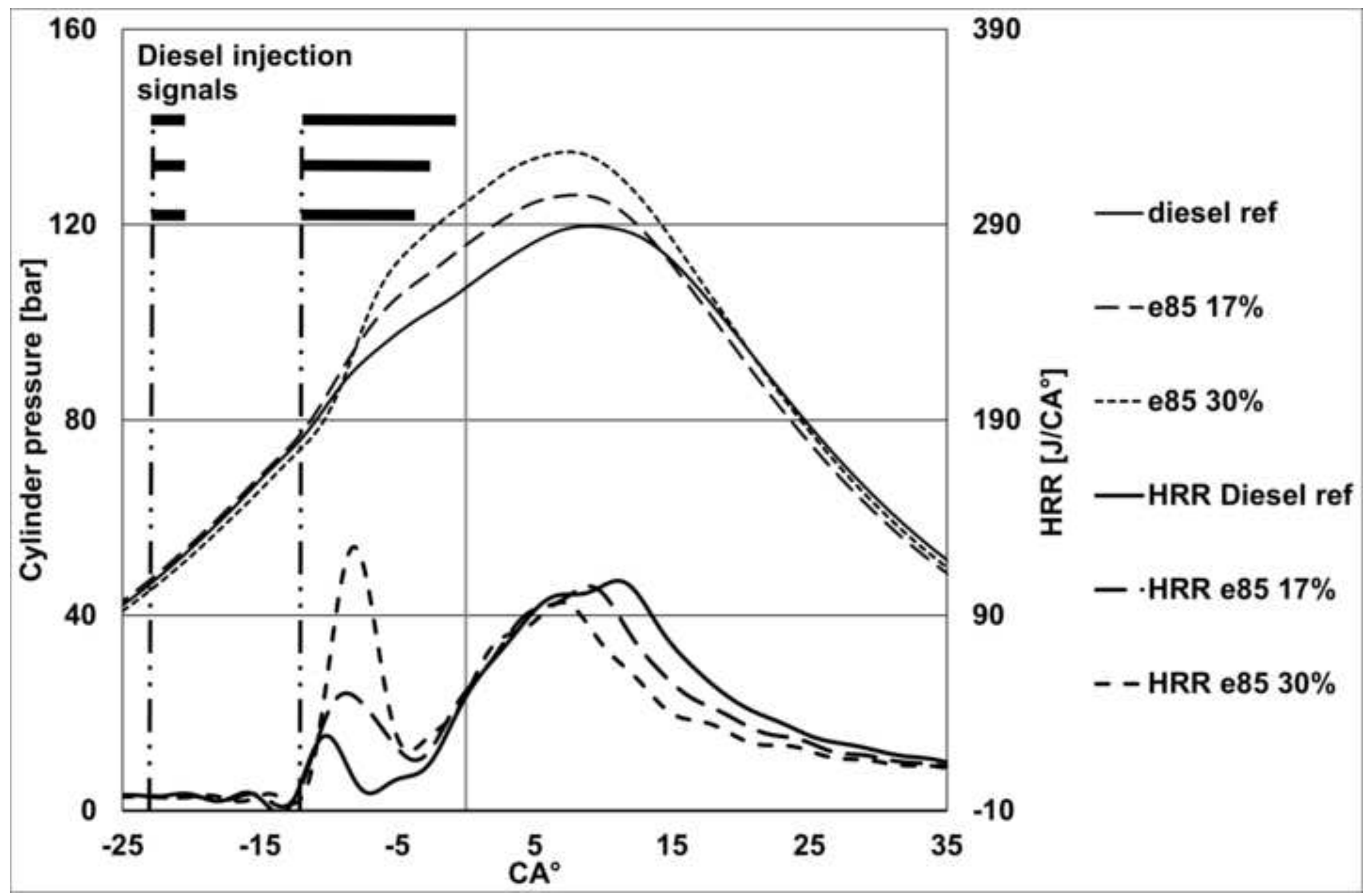




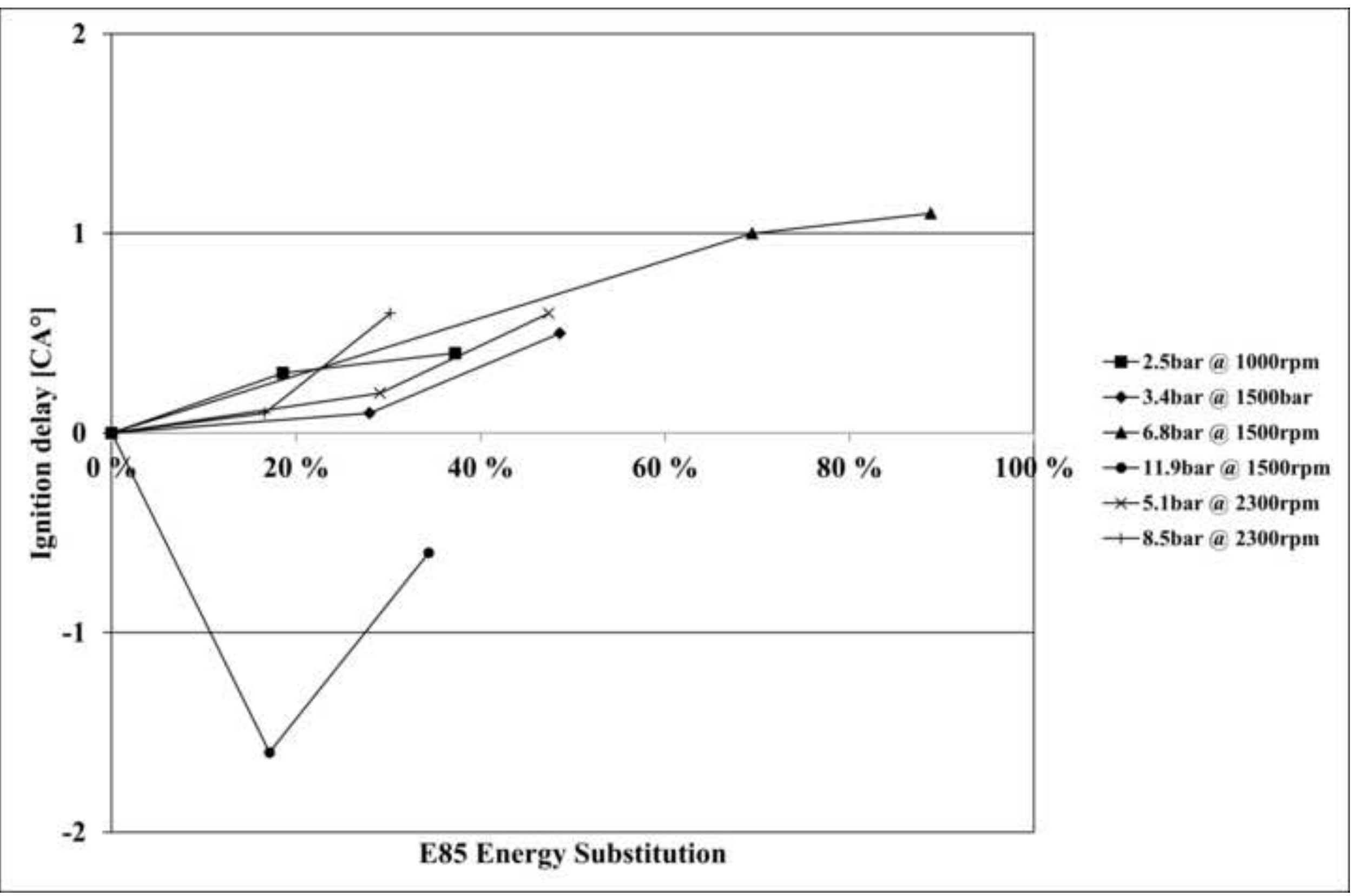




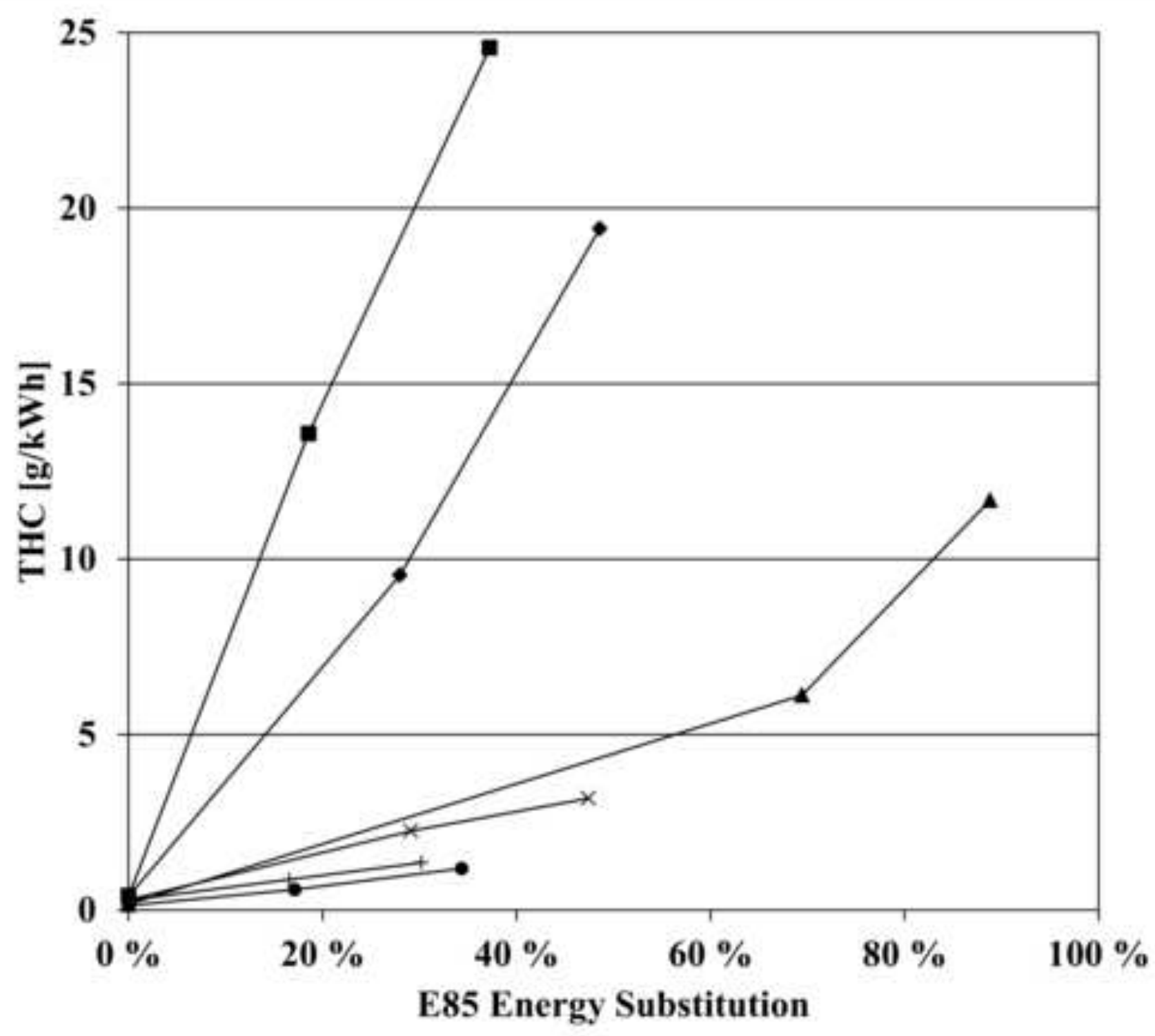

- $2.5 \mathrm{bar}$ a 1000rpm

--3.4 bar a 1500bar

\-6.8bar@1500rpm

-11.9 bar $@$ 1500rpm

*5.1bar a 2300rpm

+8.5bar a 2300rpm 


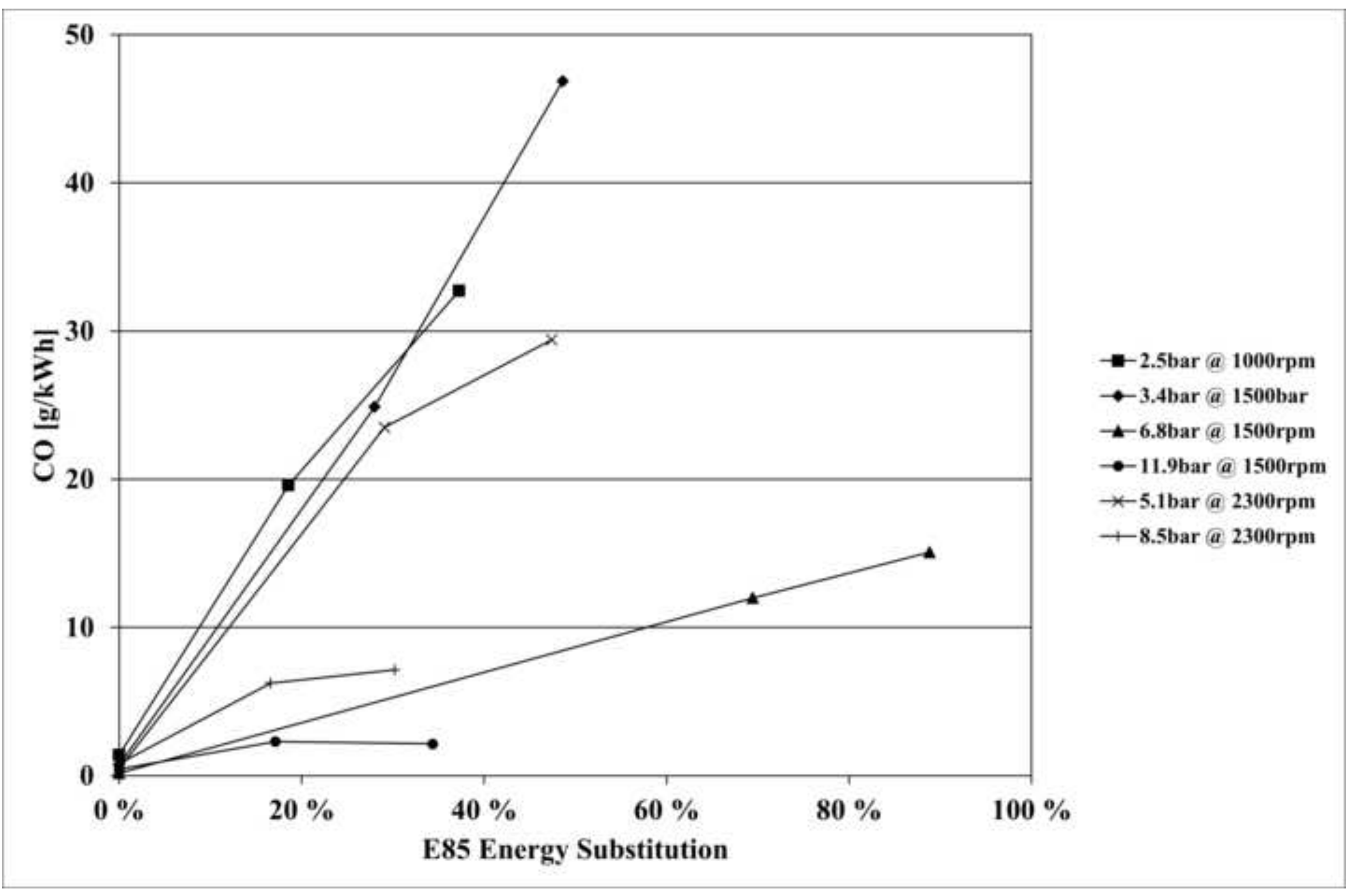




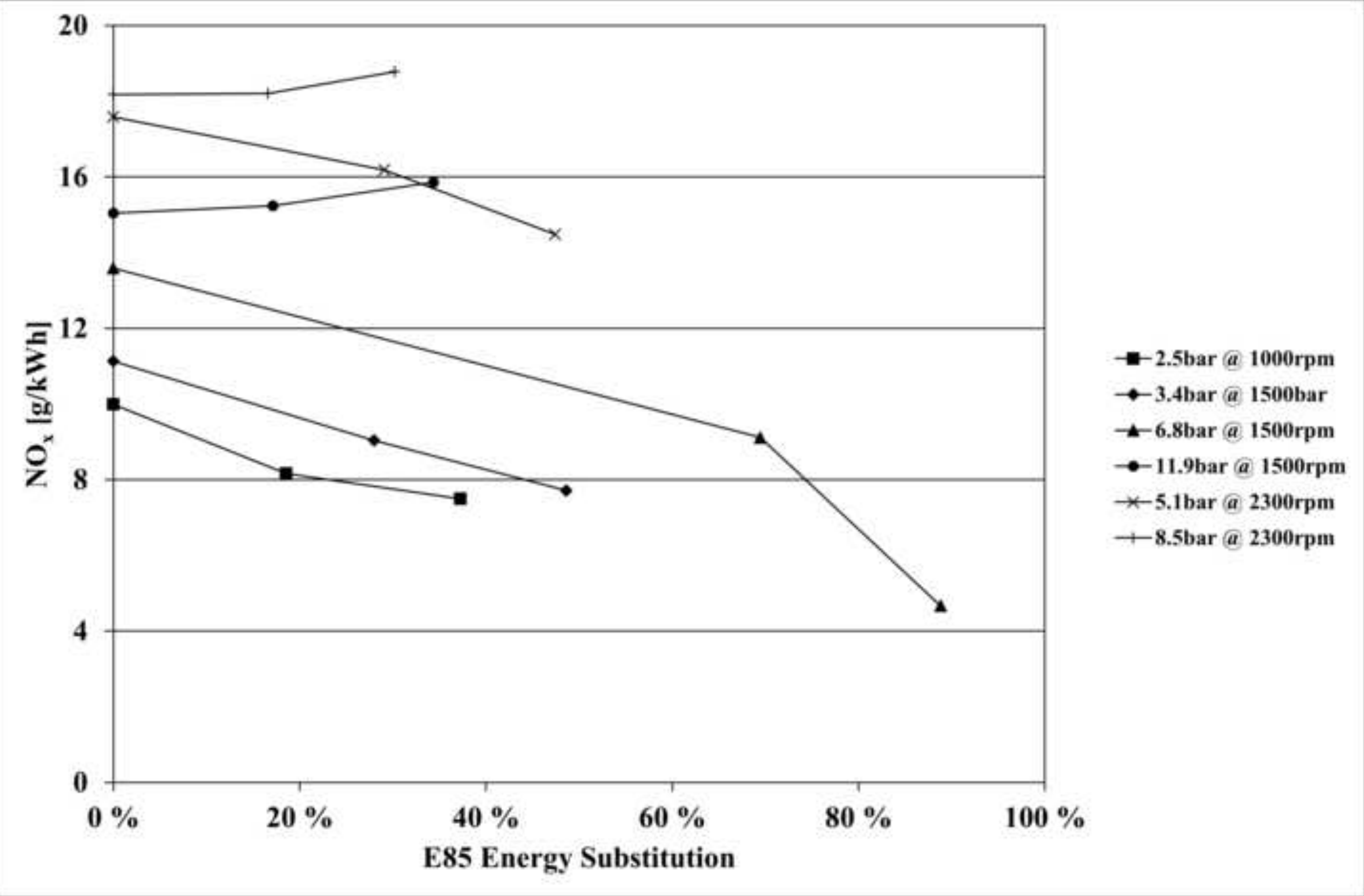




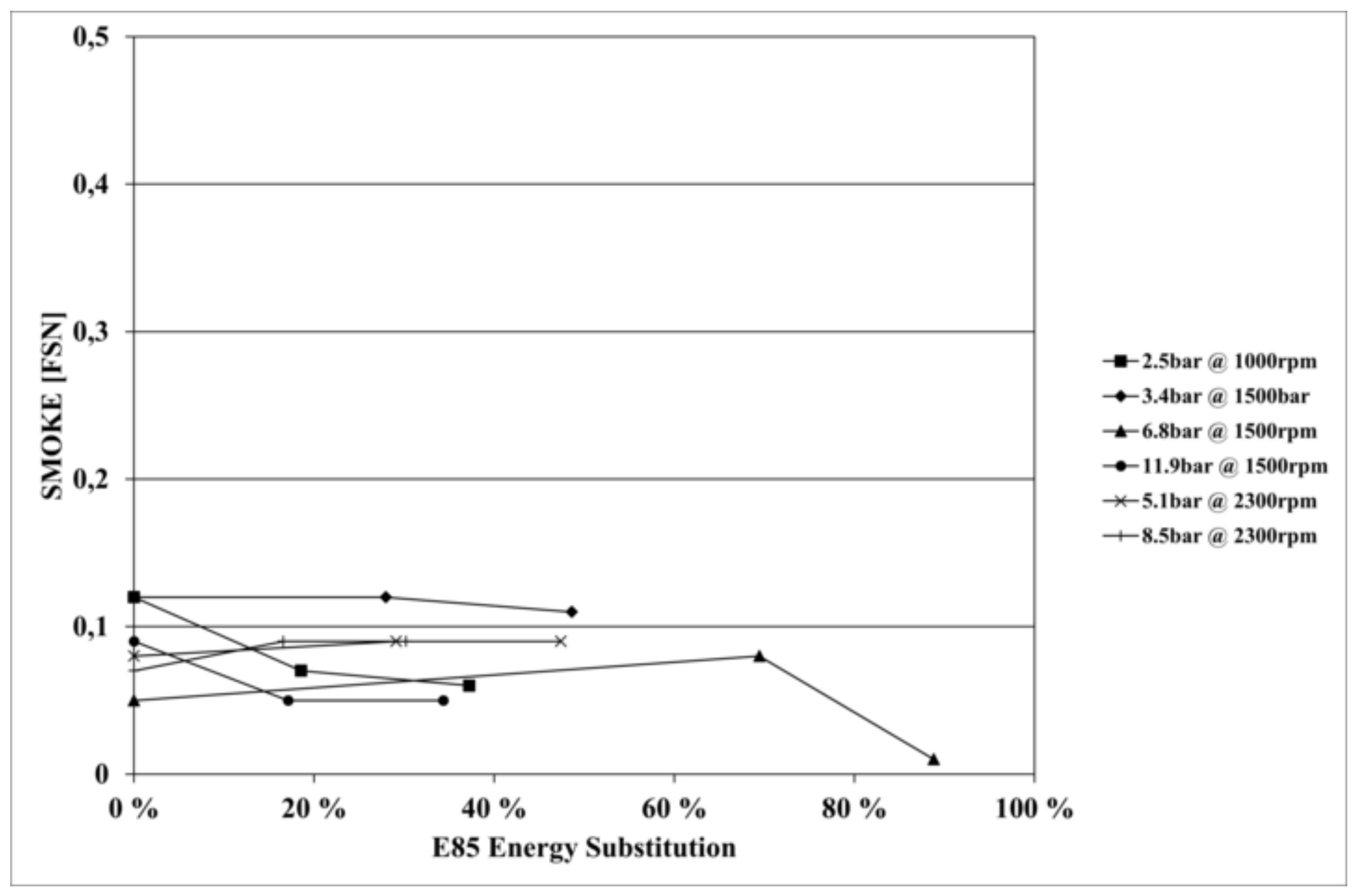




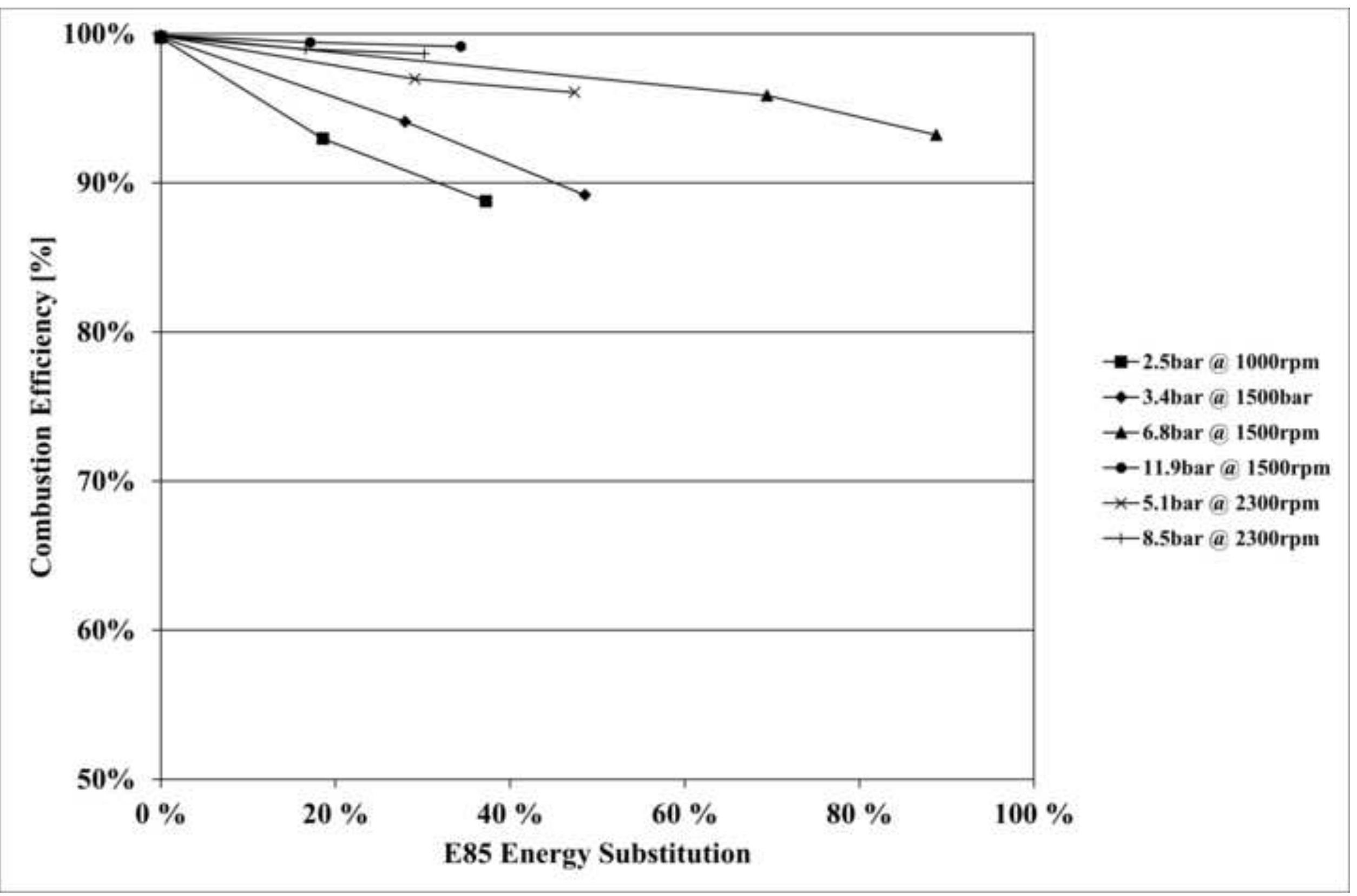




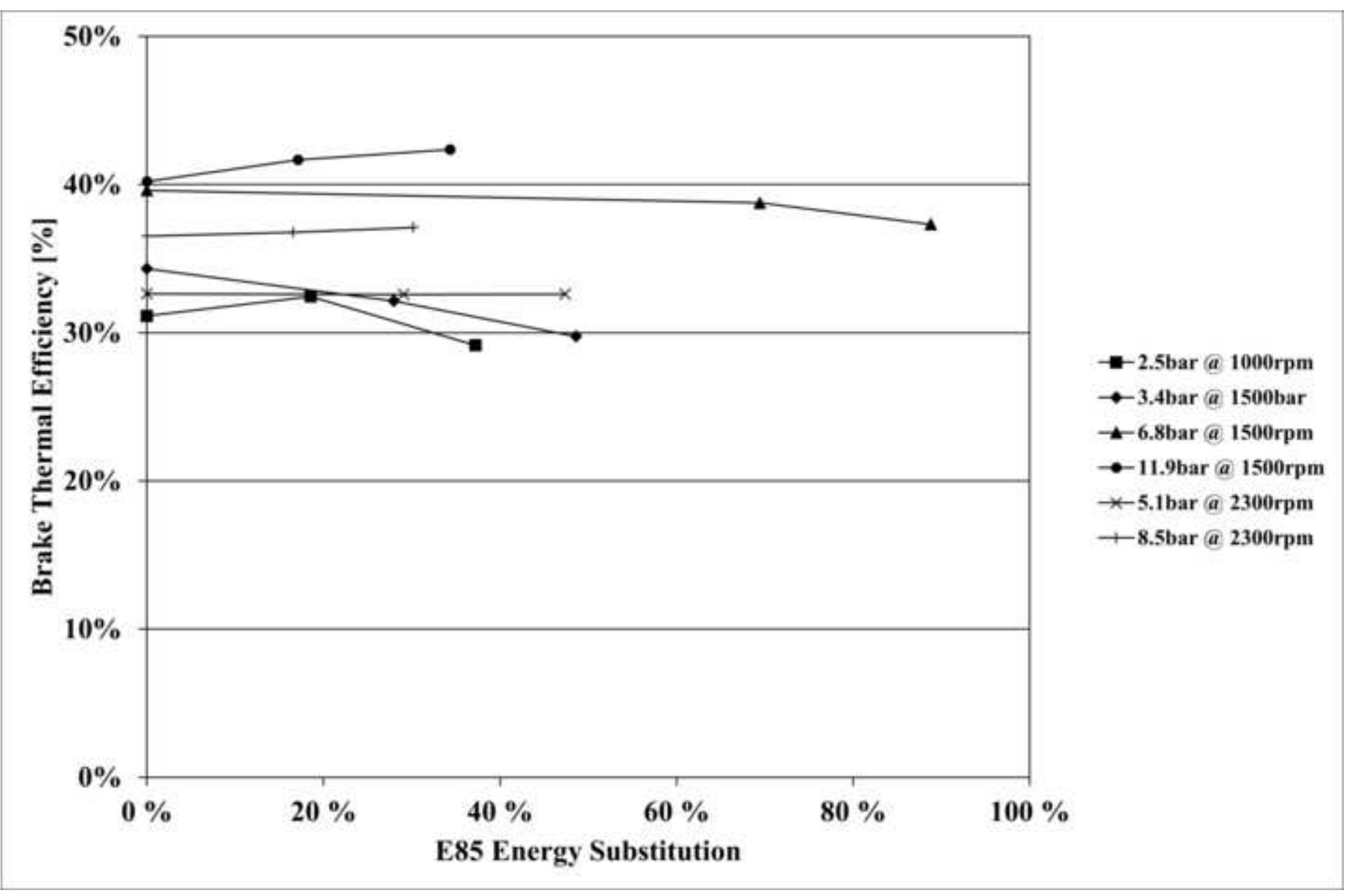




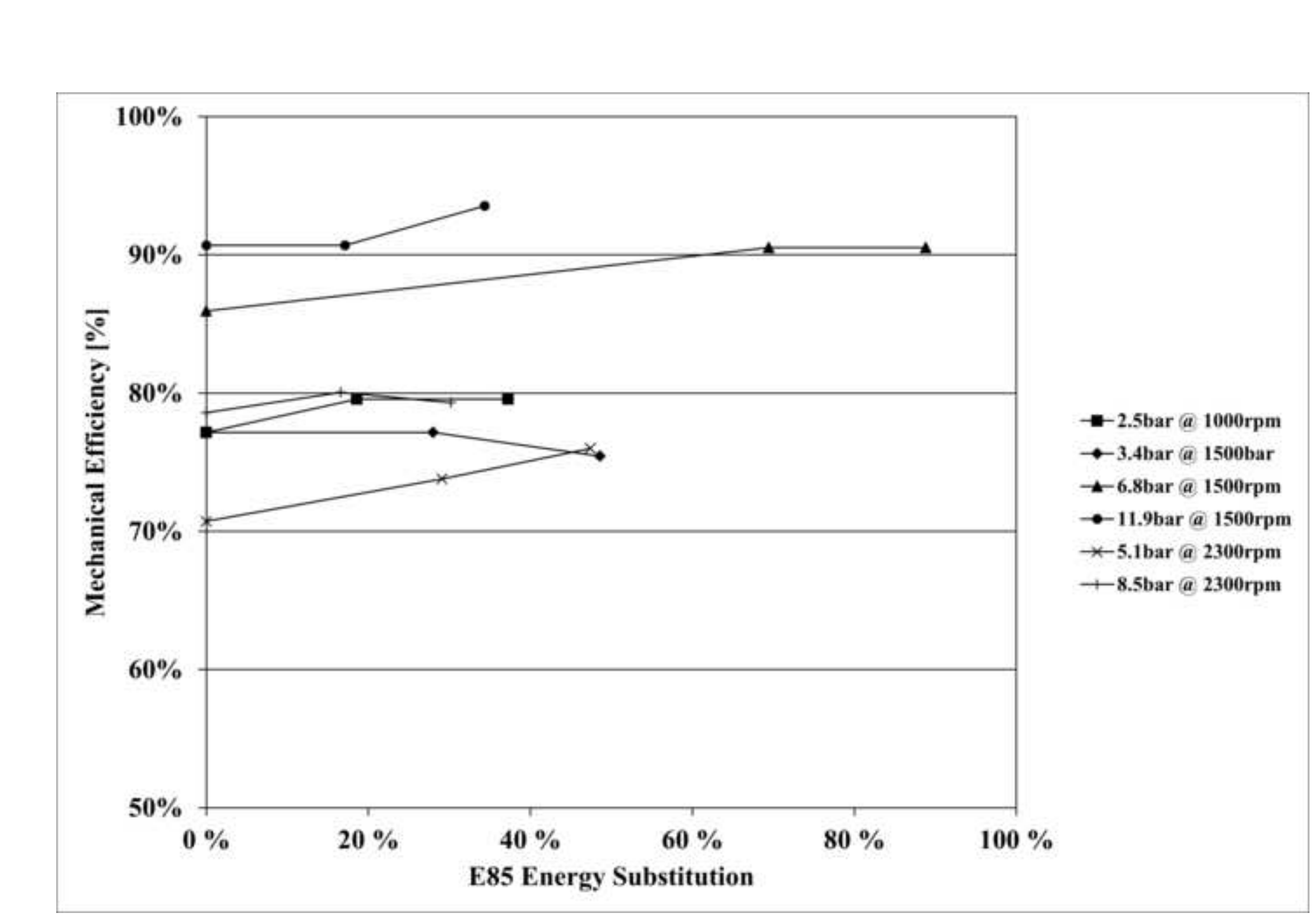




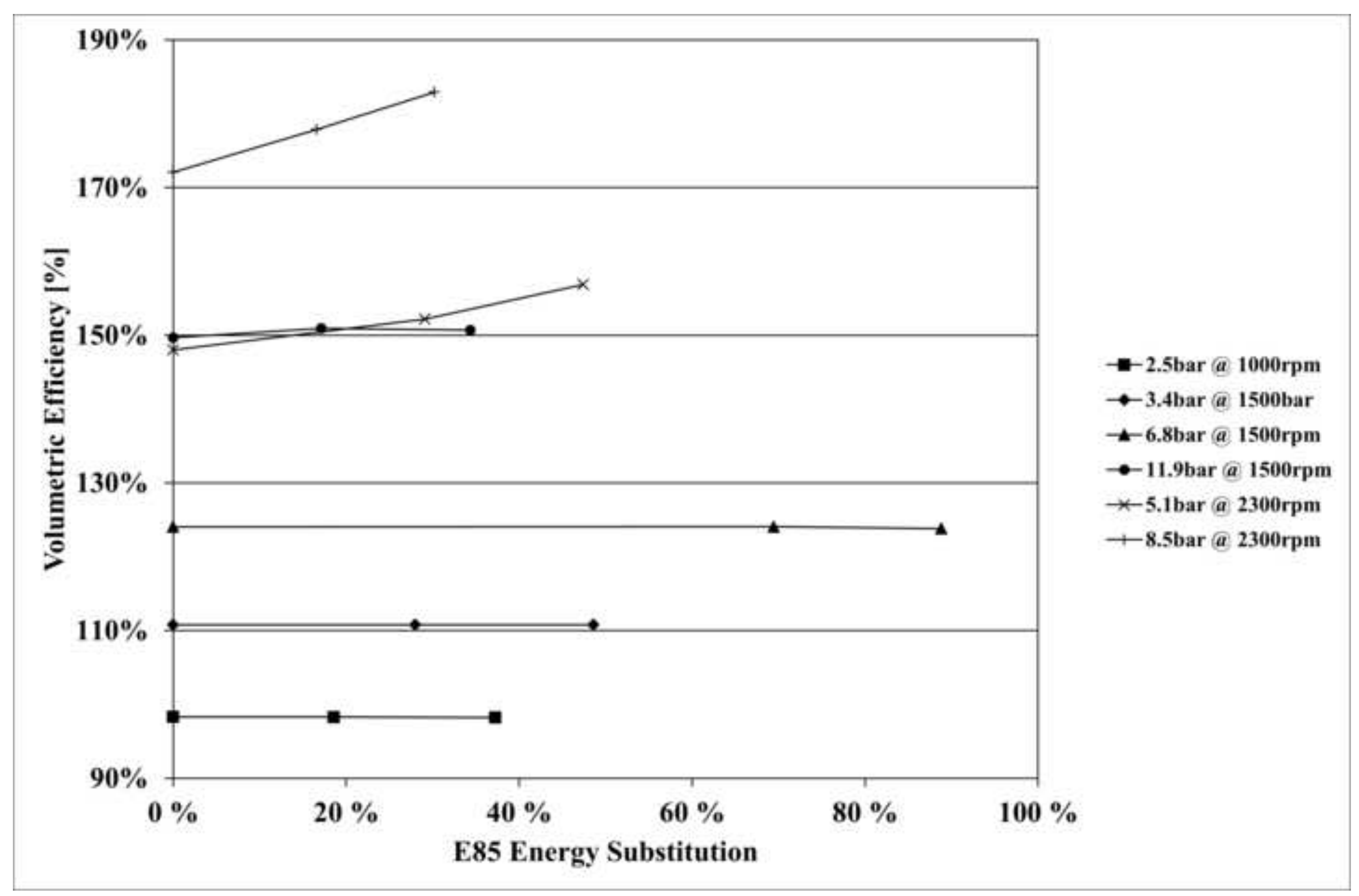

